\title{
THE NUCLEAR PATTERN OF THE NON-TECTAL PORTIONS OF THE MIDBRAIN AND ISTHMUS IN RODENTS
}

\author{
LOIS A. GILLILAN \\ Dr. Louis Merwin Gelston Fellow, Medical School, \\ University of Michigan, Ann Arbor \\ Department of Anatomy, University of Pittsburgh, Pennsylvania \\ FOURTEEN PLATES (TOURTEEN FIGUREs) \\ INTRODUCTION
}

The primary object of this investigation on the rodent brain up to the present time has been the determination of the location, the configuration, and the cell types of the various nuclear groups. The normal fiber pattern of the midbrain is being worked out and will be reported subsequently. A full discussion of the functions of the region and of the variety of conflicting experimental data cannot be undertaken until the study is complete.

Because of the necessity for correlating and standardizing the terminology to fit the whole group of mammals, reference should be made frequently to the figures in order to orient the various nuclei to the region rather than relying upon the names used.

The material studied comprises serial sections of three albino rat brains, two cut transversely and one cut sagittally, two transverse mouse ${ }^{1}$ series and one white domestic rabbit brain, all stained with toluidin blue. For the generous grant which made possible this research the writer wishes to express grateful acknowledgment to the Horace H. Rackham School of Graduate Studies of the University of Michigan.

\footnotetext{
1 This material was made from the hybrid strain used by Doctor Little and his associates in the cancer research program carried on by them at The University of Michigan.
} 
THE PERIVENTRICULAR GROUPS

\section{General areas of periventricular gray}

The periventricular gray below the fourth ventricle in the frontal pontine region is continuous forward with the central gray about the cerebral aqueduct. This gray is, for the most part, undifferentiated and composed of small cells with a few occasional larger neurons. Castaldi ('23) has subdivided the central gray into several regions, namely: a mediodorsal nucleus, a laterodorsal nucleus, a lateroventral nucleus and a ventral nucleus of the central gray.

In the rodent material available, a dorsal, a lateral, and a ventral portion have been distinguished (figs. 2 to 6,11 , and 13). These divisions of the central gray are marked by sulci running longitudinally through the aqueduct, but they are more evident at some levels than at others. The chief advantage of the grouping is a functional one based on the connections of the nuclear groups, as will be pointed out elsewhere.

In the rat and the rabbit a particularly dense group of cells, to which the term of nucleus centralis lateralis has been applied here (figs. 2 to $4, \mathrm{z}$ ), occurs in the lateral area of the central gray in rostral mesencephalic planes. The neurons are slightly larger than the general undifferentiated type found in the central gray, and therefore may be easily identified even in the mouse, in which form the nucleus is not very evident. This particular cluster of cells lies at planes through the nucleus of Darkschewitsch and, in the rat and the mouse, extends caudalward to the rostral border of the oculomotor complex. Nucleus centralis lateralis is located in the ventral part of the lateral nucleus of the central gray and should not be mistaken for the latter.

\section{Nuclear groups associated with the posterior commissure}

The posterior commissure is regarded as forming the anterior superior limit of the mesencephalon. The cells which make up its nucleus extend caudalward forming two large masses (a lateral or magnocellular group, nucleus interstitialis magnocellularis commissurae posterioris, and a medial central subcommissural group, nucleus subcommissuralis commissurae posterioris of Kuhlenbeck and Miller, '42) on either side of the outspreading commissural fibers (figs. 1 and 14). In the rabbit these cell masses keep a position well dorsolateral; but in the mouse the nucleus becomes somewhat elongated and curves ventrally around the lateral nucleus of the central gray. The disposition of the cells seems to be dependent upon the arrangement of the commissural fibers and undoubtedly on the embryological 
development. A few small stellate cells scattered among the fibers and extending across the midline and those cells lying between the laterally spreading fibers, together with a fairly large group at the rostral end of the commissure, make up the intracommissural (or interstitial) portion of the nucleus (figs. 1 and 2 ; nuclei interstitialis principalis, interstitialis supracommissuralis and medianus infracommissuralis commissurae posterioris of Kuhlenbeck and Miller, '42); the rostral cluster is not so prominent in the mouse as in the rat or the rabbit. Of the magnocellular, intracommissural and central subcommissural portions associated with the nucleus of the posterior commissure, the magnocellular has been most neglected, although Castaldi ('24) described it in the guinea pig and stated that, in the rabbit, there is only a simple indication of it.

The nucleus of Darkschewitsch (figs. 1 to 3 ) is primarily composed of medium-sized and stellate cells having large nuclei. The group is located in the lateral margin of the central gray, dorsal to the interstitial nucleus of the medial longitudinal fasciculus with which it is fused in the mouse and the rabbit. In the rat, the cells are organized into an oval mass. The nucleus of Darkschewitsch extends caudalward to planes through the rostral pole of the Edinger-Westphal nucleus.

In Ramón y Cajal's ('11) account of the rabbit, cat and dog, the term "nucleus of Darkschewitsch" was assigned to the nuclear gray in the ventrolateral margin of the central gray dorsal to the interstitial nucleus of the medial longitudinal fasciculus. From that time, "nucleus of Darkschewitsch" has been used to mean the dorsal nuclear group (which is more properly a ventral nucleus of the posterior commissure), and the ventral nucleus has been called the nucleus interstitialis of Cajal by most observers. Castaldi ('24) has described the nucleus of Darkschewitsch in the guinea pig.

\section{Eye-muscle nuclei}

Oculomotor complex. In rodents, a group of cells representing nucleus medianus anterior (nucleus Edinger-Westphal pars rostralis, fig. 3) appears in the midline immediately anterior and slightly ventral to the Edinger-Westphal nucleus. It is distinct from this latter nucleus and may be recognized by its somewhat elongated neurons (the cells are oval in the mouse) that stain deeper than those of the Edinger-Westphal group. The nucleus of these neurons is excentric and is not prominent. Apparently some authors consider nucleus medianus anterior as part of the Edinger-Westphal nucleus (Castaldi, '24, note p. 223), although Ariëns Kappers, Huber and Crosby ('36) stated that in suitably prepared human material nucleus medianus anterior is a separate nucleus. In all probability this nucleus is part 
of the oculomotor group and most rostral part of the so-called EdingerWestphal complex. Brouwer ('18) identified a nucleus medianus anterior in rabbit and guinea pig as a single mass rostral to and separate from the Edinger-Westphal nucleus. Nucleus medianus anterior is old phylogenetically, a forerunner of the Edinger-Westphal nucleus and therefore small in mammals, according to Brouwer. A paired nucleus medianus anterior at levels of the red nucleus was described for rodents by Zweig ('21).

The gray forming the main (or caudal) Edinger-Westphal nucleus (fig. 4) is a thin band of small, spindle-shaped cells which lies between and slightly dorsal to pars ventromedialis of the principal oculomotor nucleus. It is a midline group that splits imperfectly into two parts, most markedly in its dorsocephalic portion. This nucleus of the rat shows more separation than does that of the other two rodents considered here. Castaldi ('24) described it in the guinea pig, including with it nucleus medianus anterior under the name of Edinger-Westphal nucleus.

The cells of the chief oculomotor nucleus (fig. 4) are large multipolar neurons of the motor type which form two masses close to the midline. The processes of the cells are long and there is a reticulum within the nucleus. Two parts are intinguishable in rodents: a dorsolateral division or nucleus which may be continuous caudally with the trochlear nucleus, and a ventromedial division or nucleus that extends farther rostrally and is situated nearer the midline. The neurons of the dorsolateral nuclear group are somewhat scattered and may even lie among the fibers of the medial longitudinal fasciculus; the ventromedial nucleus is more compact. There is no spatial division of these two groups, and the distinction is based on position and arrangement of cells. In the rabbit the cells of the dorsolateral division show a tendency to form four subgroups which make an orderly crescent over the ventromedial nucleus. There is no central nucleus of Perlia in rodents. Brouwer ('18) found no connection in the midline (nucleus of Perlia) between the two oculomotor groups.

The oculomotor nuclear group lies at superior collicular levels in planes caudal to and coexistent with the posterior portion of the red nucleus. Emerging fibers of the oculomotor nerve cross the medial longitudinal fasciculus and the red nucleus. The nucleus of Darkschewitsch and nucleus interstitialis of the medial longitudinal fasciculus are lateral and rostral with respect to the oculomotor gray. (Compare fig. 4 with figs. 2 and 3.)

Trochlear gray (fig. 5). This nucleus lies at the anterior pole of the inferior colliculus and is usually continuous with the dorsolateral oculomotor nucleus in the mouse. Sometimes in the rat, and more often in the rabbit, there is a slight gap between them. Nucleus trochlearis 
lies a little more lateral than the oculomotor nucleus and immediately dorsal to the medial longitudinal fasciculus, among the fibers of which some cells may be seen. It is bounded medially and dorsally by the dorsal nucleus of the raphé.

The neurons giving rise to the trochlear nerve are of the same type as those of the oculomotor nucleus, but they are slightly larger and stain more deeply with toluidin blue. The nucleus of the cells is dark, and the nucleolus is difficult to see. Again the long dendrites form a plexus within the nuclear mass.

In one rat brain a distinct accessory trochlear nucleus was found on the left side, lying some distance caudal to the main nuclear group. An accessory group was found in the rabbit series on the left side but none in the mouse on either side.

Nucleus trochlearis, as well as the oculomotor nucleus, has been described at length for the guinea pig by Castaldi ('24), for the mouse by Ramón y Cajal ('11), and for other mammalian forms by many more investigators. A good review of the literature may be found in the Ariëns Kappers, Huber and Crosby ('36) text.

\section{Dorsal nucleus of raphé (figs. 5 to 7,12 )}

In rodents a midline unpaired nucleus begins at the rostral tip of nucleus dorsalis tegmenti. In the rat, three groups of cells form a very large and conspicuous mass in the lower mesencephalon: some deep-staining, spindle-shaped, multipolar cells lie between the bundles of the medial longitudinal fasciculus. A paired band of gray overlies nucleus dorsalis tegmenti dorsomedially, and these cells increase in number rapidly as the nucleus is traced forward. The two masses join to form a single nucleus, which then extends ventralward to replace the large-celled group mentioned above. This dorsal group of cells corresponds to Castaldi's ('23) nucleus incertus.

At its greatest development anterior to nucleus laterodorsalis, the dorsal nucleus of the raphé resembles a tree; there is a medial portion, a dorsal portion that branches to the left and right just below the ventricle and a ventral part that branches to the left and right immediately above the bundles of the medial longitudinal fasciculus. There is also a lateral portion of this nucleus which lies between the dorsal and ventral branches; the cells of this lateral part, however, are scattered and vary in their lateral extent from section to section. At levels through nucleus trochlearis, the medial and dorsal groups become more diffuse and fused, as if the tree had acquired its ful' foliage. The dorsal and lateral parts become entirely separate from the ventromedian at the level of transition between the trochlear and oculomotor nuclei. The ventromedian group then drops out and only 
the dorsomedian portion persists a short distance beyond the caudal end of the oculomotor nucleus.

Caudally the dorsal tegmental nucleus lies lateral to the central division of the dorsal nucleus of the raphé, but anteriorly the ventral nucleus of the central gray bounds the lateral borders. The medial longitudinal fasciculus, the trochlear nucleus, and the oculomotor nucleus successively lie ventrolaterally.

Nucleus dorsalis of the raphé is also very large in both the mouse and the rabbit. The central portion is first seen caudally, and this is the principal cell group of the nucleus in the rabbit as the lateral portion is lacking for the most part. In the mouse the dorsolateral wings extend as far forward as the central portion from which they become separated.

The dorsal nucleus of the raphé is made up of large and medium sized, closely grouped, stellate cells which have flakey Nissl granules. The nucleus of the cell is not prominent, but the nucleolus is well marked. On the whole this nucleus is deep-staining and well-defined.

\section{Laterodorsal tegmental nucleus (Castaldi, '23) (figs. 8, 11, 12)}

This is a crescentic or comma-shaped nucleus lying lateral and slightly ventral to nucleus dorsalis tegmenti and at approximately the same levels. The nucleus has two parts: a caudodorsal portion made up of small and medium-sized, deep-staining cells, organized into a definite nuclear mass, and a rostroventral group composed of more scattered, larger cells extending into the dorsocaudal part of nucleus lateralis profundus mesencephali.

Rostral to the dorsal tegmental nucleus the laterodorsal nucleus shifts medialward to occupy the position held by the former nucleus. At these levels it also becomes more oval in shape. Laterally the laterodorsal nucleus may touch on the mesencephalic root of the trigeminal nerve and its nucleus. Cells of the ventral nucleus of the central gray lie dorsal and, to a varying degree, dorsolateral. In the rostral planes some of the elements of this ventral nucleus are also found between the laterodorsal tegmental nucleus and the medial longitudinal fasciculus.

\section{Dorsal tegmental nucleus (figs. 8, 11, 12)}

Nueleus dorsalis tegmenti is a round group of cells, as seen in cross section, or oval if seen in sagittal section, that differentiates from the central gray of the lower mesencephalic and upper pontine regions. It extends from a short distance behind nucleus trochlearis to the rostral end of the motor nucleus of the trigeminal nerve. It is a 
paired, compact mass lying just dorsal to the medial longitudinal fasciculus on either side of the midline. The nucleus is enclosed in a fiber capsule on all sides. Throughout the whole extent of the dorsal tegmental nucleus, the laterodorsal tegmental nucleus forms a crescentic mass lateralward and sometimes even dorsal- and ventralward. A small portion of the ventral nucleus of the central gray lies dorsomedially, and the dorsal nucleus of the raphe is ventromedial to the dorsal tegmental nucleus.

Nucleus dorsalis tegmenti extends into the caudal part of the mesencephalon for varying distances in the different rodents. In the rabbit it may be found at lower inferior collicular levels, whereas it extends to the extreme caudal border only in the rat. Castaldi ('23) considered the nucleus a part of the mesencephalic region, but in the rodents studied here by far the greater extent of the nucleus lies in the region caudal to the midbrain. Other pertinent references may be found in Ramón y Cajal ('11) and Ariëns Kappers, Huber and Crosby ('36).

The cells of the dorsal tegmental nucleus are very small, round and oval, with deeply staining cytoplasm. Dendritic processes are hard to make out, but there seem to be only two or three per cell. The axis cylinder is the only visible process in most cases.

\section{Nucleus of the mesencephalic root of $V$ (figs. 4-13)}

Beginning at the level of the chief sensory nucleus of the trigeminal nerve in the pons, the nucleus of the mesencephalic root is formed by a continuous column of large, sensory-type cells, with the greatest number at the lowest levels forming the thick base of the column. They decrease from level to level thereafter, so that the column tapers off, finally ending at the rostral levels of the oculomotor nucleus in the mesencephalon. There is an increase in the number of neurons at the level of the trochlear nucleus and a somewhat greater increase at the level of the oculomotor nuclei.

In the pons region, the mesencephalic root neurons are located at the lateral angle of the fourth ventricle, dorsal to the chief sensory and motor nuclei of the trigeminal nerve. The cells of the chief sensory nucleus extend dorsalward to meet these large sensory neurons. In the aqueduct region the column lies at the ventrolateral and, later, at the lateral aspect of the central gray; a few cells are found dorsolateral to the central gray in the mouse. None of the cells strayed dorsalward along the roots of the trochlear nerve in the anterior medullary velum. At caudal levels an oval mass of small, deeply staining cells, locus coeruleus, lies between the mesencephalic nucleus and the ventricle. These small neurons lie in brain tissue that takes 
up the toluidin blue stain, giving the locus an intensely blue appearance. The cells belonging to the nucleus of the mesencephalic root are immediately adjacent to locus coeruleus and the neurons are sometimes mingled with it. In the upper pons region caudal to its decussation the superior cerebellar peduncle lies lateral to the mesencephalic root.

Castaldi ('26) describes at great length the embryological development of the mesencephalic root together with its connections in the guinea pig. He considers this nucleus to be motor in function, as does Ramón y Cajal ('11), even though the majority of other investigators believe it to be sensory (for discussion see Ariëns Kappers, Huber and Crosby, '36). Recently Pearson ('43) has been able to follow one process of the mesencephalic root cells in human fetuses with the root of the trochlear nerve and the other into the trochlear nucleus. Golgi (1894) showed the same thing. Further comment upon this nucleus and its possible function will be reserved here, except to say that the neurons of the mesencephalic root in the rodents studied are distinctly sensory in type.

\section{MIDTEGMENTAL NUCLEAR GROUPS}

\section{Nuclear groups associated with medial longitudinal fasciculus}

Nucleus interstitialis (figs. 1 to 3 ) of the medial longitudinal fasciculus has a slightly greater rostro-caudal extent than does the nucleus of Darkschewitsch and lies ventrolateral to it. In the mouse and the rabbit, the oral end becomes fused with the nucleus of Darkschewitsch, and the two together form a large mass of somewhat deeply staining, medium-size, multipolar neurons. The interstitial nucleus extends back to the rostral pole of the chief oculomotor nucleus, where it crowds medially upon the latter. Caudally the interstitial nucleus lies lateral and superior to the oculomotor nucleus and dorsal to the red nucleus. The cells, which have long processes, form a reticulum in the course of the medial longitudinal fasciculus. Ramón y Cajal ('11) first distinguished these cells from those of the red nucleus, and later descriptions agree with the original account. Castaldi ('24) considered the interstitial nucleus to be continuous with the annular nucleus of the medial longitudinal fasciculus. Stengel ('24) commented upon the similarity between cells of the interstitial nucleus and the red nucleus in the rat, guinea pig, and the rabbit, and he believed them to belong to the same system.

The annular nucleus of the medial longitudinal fasciculus (figs. $12,13)$ is composed of small and medium-sized, dark-staining cells that form a half moon about the bundle of fibers making up the fasciculus; some of the cells lie among the fiber fascicles. This nucleus is most conspicuous in the rabbit and is reduced to a very few cells 
in the rat. The cells seem to occur in clusters, the greatest concentration being in planes through the inferior colliculus. Castaldi ('23) found this nucleus to be prominent in the guinea pig and has figured it throughout the lower midbrain region.

\section{Red nucleus (figs. 2 to 4)}

The red nucleus is a special condensation of cells derived from the tegmental area of the midbrain. It is an extremely large, paired nuclear mass occupying the medial portion of the tegmentum from a plane through the posterior third of the chief oculomotor nucleus forward to a level about half-way through the mammillary body in the caudal diencephalon of the rat and the mouse. The red nucleus of the rabbit does not extend so far forward and ends behind the mammillary body. The red nucleus is by far the most conspicuous structure in the midbrain region, primarily because of the large, multipolar neurons which make up the greater part of it in rodents. These large, deep-staining cells retain their reticular character and have long, interlacing dendrites.

Caudally these very large cells form a round to oval mass, but as the structure is traced rostrally, smaller neurons appear on the dorsal and lateral aspects of the nucleus. In the rat, the number of very large cells decreases as the medium-sized cells increase; these latter are then gradually replaced by small multipolar cells. However, a few (three to five per section) of the large neurons may be found in the ventromedial aspect of the nucleus for a considerable distance. The parvocellular portion thus forms a cap over the magnocellular part, covering dorsal, lateral and dorsomedial surfaces and finally forming a cone at the anterior end of the nucleus. In sagittal section the red nucleus is egg-shaped, the small end projecting forward and the blunt end backward.

In the mouse, the parvocellular part of the red nucleus likewise encapsulates the large-celled portion rostrally, dorsally and laterally. The small cells in the rabbit extend back for a considerable distance about the larger cells, with a great number of them lying ventrolaterally. The rostral cone of small cells is diminished in this animal to such a degree that it only touches the ventral thalamus. Large and medium-sized cells are found the entire length of the nucleus, though they decrease in number at the anterior end.

The large-celled portion of the red nucleus of rodents is not so large as that in earnivores, although the number of cells is much greater than can be found in the nucleus of primates and man. The parvocellular portion is not well developed in rodents and is least well developed in the rabbit. In connection with this last statement, 
it is interesting to note that substantia nigra in the rabbit is similarly less extensive and less prominent than in the rat.

The entire red nucleus is surrounded by a capsule of fibers, primarily from the dento-rubro-thalamic, strio-rubral, and rubro-spinal systems. The neurons of the nucleus fall into four classes: (1) giant cells of the motor type, which appear in the most caudal portion only and which are stained moderately heavily with toluidin blue; the nucleolus is prominent in the inconspicuous nucleus, and the cell processes are long and thick; (2) large cells of the same general type as the giant cell; (3) medium-sized cells, with more lightly stained cytoplasm; (4) small cells, stellate and multipolar, with eytoplasm which stains very lightly and a nucleus so darkly stained that the nucleolus is difficult to see.

From the wealth of literature on the red nucleus, the description and reconstruction made by Davenport and Ranson ('30) for rabbit and cat very accurately fit the findings of this study, and Ramón $y$ Cajal's ('11) cytological picture is also agreeable. No pigment was discovered in the gray surrounding the red nucleus, as was described by Foix and Nicolesco ('25). Winkler and Potter ('11) figured the nucleus in their rabbit atlas, as being composed of large, mediumsized and small cells.

\section{Deep mesencephalio gray (figs. 2 to $6,13,14$ )}

Again, it is advantageous to describe the tegmental regions of the midbrain by beginning at the caudal end. In the frontal pontine and caudal mesencephalic region a group of medium to large reticular cells lies ventrolateral to the medial longitudinal fasciculus and ventromedial to the superior cerebellar peduncle. Nucleus mesencephalicus profundus, also called nucleus lateralis profundus mesencephali, is directly continuous forward with this ventrolateral nucleus of the pons. The pontine tegmental gray lies ventral to the deep lateral nucleus through most of the inferior collicular region in the plane in which the sections are cut and is eventually replaced by the ventrolateral division of nucleus mesencephalicus profundus. Caudally the large-celled element of nucleus laterodorsalis tegmenti spreads ventrolateralward through the medial longitudinal fasciculus into nucleus lateralis profundus.

At levels behind and in front of the red nucleus pars magnocellularis large cells occupy dorsal, lateral and ventrolateral positions and constitute those divisions of nucleus mesencephalicus profundus. At planes through pars magnocellularis of the red nucleus, there are very few large neurons of nucleus mesencephalicus profundus, and there is some variation in the number of cells from level to level 
throughout. Both the cell eytoplasm and nucleus stain lightly, but the nucleolus is usually prominent. Cells of the red nucleus and nucleus interstitialis are similar to those of the deep lateral tegmental nucleus, indicating their origin.

The mesencephalic tegmentum is a region of passage of many fibers, and this accounts for the reticular character of the cell elements. This great diffuse area is probably the site of correlation and transmission of many different types of impulses. The great variety of experimental data can be explained on this basis, but a discussion of the results must be reserved until a study of the fiber tracts is completed. For references see the Ariëns Kappers, Huber and Crosby ('36) text.

\section{Ventral tegmental area of Tsai (figs. 3,4)}

This area lies in the ventral portion of the midbrain, medial to the cerebral peduncle and substantia nigra and lateral to the interpeduncular nucleus. In the mouse and the rat the area is small, being crowded almost to non-existence by such structures as the emerging roots of the oculomotor nerve, nucleus interpeduncularis, and the medial fibers of the cerebral peduncle. The rabbit brain, however, has a fair sized ventral nucleus, and in this respect closely resembles that of the embryo pig (Gillilan, ' $43 \mathrm{~b}$ ).

Passing through the ventral tegmental area is the mammillary peduncle with its associated nucleus. The latter appears to be a condensation of cells derived from the ventral tegmental area. The nucleus of the supramammillary decussation bounds the rostromedial aspect of the area, and the ventral tegmental cells spread dorsolateralward into substantia nigra and the nucleus of the basal optic root. Dorsocaudally it runs into the nucleus of the decussation of Forel. The neurons are small, medium-staining, and multipolar in type.

In 1932 Papez described an interstitial nucleus for the mammillary peduncle in the nine-banded armadillo. Small, deep-staining cells can be identified in the rat and the rabbit along the dorsal and dorsomedial portion of the mammillary peduncle as a more dense group of neurons within the ventral tegmental nucleus of Tsai, and partially embedded in the bundle as the latter runs along the sides of the anterior third of the interpeduncular nucleus and the posterior quarter of the mammillary body (figs. 3,4 ). These cells are encroached upon by the medial tip of substantia nigra zona compacta, by the nucleus of the ventral tegmental decussation and, in the rabbit, by the nucleus of the supramammillary decussation or commissure of Forel. In some sections a clear localization of the nucleus is difficult. It seems to be 
inseparable from the ventral tegmental nucleus of Tsai through which the peduncle runs. In the mouse, only a few of the cells can be found in the course of the peduncle itself; the nucleus as such could not be identified.

Nucleus medialis profundus (figs. 7, 8, 12, 13)

Nucleus medialis profundus, so called by Castaldi ('23), is nucleus ventralis tegmenti of von Gudden (1870), Ramón y Cajal and others (see Ramón y Cajal, '11, and Ariëns Kappers, Huber and Crosby, '36). It is caudal to the trochlear nucleus and ventral to the medial longitudinal fasciculus, which separates it from the dorsal tegmental nucleus above. The most rostral portion of the nucleus overlies the most caudally decussating fibers of the superior cerebellar peduncle. The cells of the nucleus are small, medium-sized, multipolar neurons with deeply staining cytoplasm. They are fairly closely packed into an oval mass that is very conspicuous in the region.

Marginal nucleus of the superior cerebellar peduncle (figs. 7 to 12)

At pontine levels a considerable group of small stellate cells forms a crescent over the dorsolateral surface of the superior cerebellar peduncle (Castaldi, '23). At these lower planes the dorsal nucleus of the lateral lemniscus is embedded in its dorsal edge. The nucleus decreases in size farther rostrally and finally disappears in the lower tectal region except for a few stellate cells, which slip around the ventral tip of the peduncle to the medial inferior border. A few of these cells can be found among the fibers. In the rat, and to a lesser degree in the mouse and the rabbit, a small group of mediumsized stellate cells is found at the inferior pole of the peduncle throughout the inferior collicular region. At a casual glance this may be taken for a small red nucleus, and indeed it might actually be so. It is thought that these neurons at one time in the course of phylogeny and ontogeny did belong with the red nucleus, but that through neurobiotactic influences they have taken up a position near the peduncle and have not joined the main mass which is more rostral. An observation confirming this point shows that the number of larger cells in the red nucleus proper is somewhat smaller in the rat than in the mouse and the rabbit. In the two latter animals the fewer aberrant cells are scattered along the under side of the peduncle, and consequently they are less evident. Winkler and Potter ('11) figure a dorsal and a ventral nucleus of the brachium conjunctivum for the rabbit in their figures 22 to 27 . 


\section{Cuneiform area}

The cuneiform area (see figs. 5-7, 9, 10, 12, 13) appears posteriorly at the inferior caudal pole of the inferior colliculus. As its name implies it is cuneiform in shape, sometimes triangular and more often rhomboidal. In all the rodents this nuclear mass attains considerable size and its cell type is similar to that of the central gray and of the principal nucleus of the inferior colliculus. One tip of this area projects up into the angle formed by the central gray and the inferior colliculus. Fibers of the lateral lemniscus pass lateral, dorsal and inferior to the cuneiform area, and a considerable number enter the nucleus in its rostral portion. The mesencephalic root of $\mathrm{V}$ and its cells are found on the medial aspect of the area, and the larger cells of the dorsal nucleus lie in the inferior border of the area rostrally as mentioned above. The cuneiform area extends throughout the inferior collicular region and, as designated here, includes both the cuneiform area and the nucleus of Kölliker-Fuse as figured by Castaldi ('23).

\section{Certain pretectal and subtectal components of tegmentum}

Nucleus pretectalis (figs. 1, 2, 14). Nucleus pretectalis lies at the extreme rostral pole of the mesencephalon and extends into the caudal portion of the diencephalon. It has been discussed with the thalamic nuclei of the rat by Gurdjian ('27) and for various other mammals by Ramón y Cajal ('11), Le Gros Clark ('29, '30, '31), Papez ('32), and Bodian ('40). From the confusion of names applied to nuclei of this area (see Ariëns Kappers, Huber and Crosby, '36; also Gillilan, ' $43 \mathrm{~b}$ ), we have agreed to call the pretectal nucleus that group of cells which lies lateral to the habenular nuclei, inferior to the anterior pole of the superior collicular gray, and above the nucleus of the posterior commissure.

At about its midpoint, the pretectal nucleus is a more or less pie-shaped mass with the curved, dorsal aspect underlying the deep strata of the superior colliculus. At its lateral tip, pars posterior of the lateral thalamic nucleus intervenes between the pretectal nucleus and the medial and lateral geniculate nuclei. The posterior thalamic nucleus fills in the niche between the pretectal and the lateral nucleus. At its most caudal end, nucleus pretectalis lies dorsomedial to the medial geniculate nucleus and dorsal and dorsolateral to the suprageniculate nucleus and the nucleus of the posterior commissure respectively.

This same relationship holds for the mouse and the rabbit as well. Nucleus pretectalis in rodents is primarily a diencephalo-mesencephalic structure, keeping a rather superficial position as it is shifted from dorsomedial to ventrolateral by the caudally overriding tectal gray. 
It is important to note that the pretectal nucleus is always dorsal to the nucleus of the posterior commissure.

The cells of the pretectal nucleus are small, oval and triangular neurons, which stain moderately with toludin blue. The nuclei and processes are not conspicuous. In the mouse there are some larger cells in this nucleus in addition to the small-celled element.

Papez ('32) has indicated both a pretectal area and a pretectal nucleus in armadillo. In the rodent material there is an area at the extreme rostral pole of the mesencephalon lying dorsal to the posterior commissure, which corresponds to Papez's pretectal area and to the pretectal area of Rioch ('31), Ingram, Hannett and Ranson ('32), and others, in carnivores. Area pretectalis is primarily an undifferentiated mesencephalic cell mass which fuses with stratum griseum intermediale of the optic tectum, and it should not be confused with nucleus pretectalis as described by Gurdjian ('27) and this author.

Large-celled nucleus of optic tract (figs. 1, 14 M). A small group of somewhat scattered large cells is found in the caudal diencephalon and anterior mesencephalon in the course of the optic fibers going to the superior colliculus and pretectal complex. These fusiform cells have pale to medium-staining cytoplasm and an inconspicuous nucleus. The group can be located throughout the region at the dorsolateral tip of the pretectal nucleus, and it shifts from dorsomedial to ventrolateral as does this latter group in reading a series caudalward. The large-celled nucleus of the optic tract is best seen in the rabbit and rather difficult to pick out in the mouse. It is possible that the larger cells found in the pretectal nucleus in the latter belong to the large-celled nucleus of the optic tract.

This nucleus has been located in several mammalian forms. It has been called nucleus lenticularis mesencephali in the dog by Rioch ('29), in the armadillo by Papez ('32) and in the cat by Ingram, Hannett and Ranson ('32). This name has been applied on the supposition that this nuclear group represents the similarly designated submammalian nucleuss (De Lange, '13; Huber and Crosby, '26; and others). Ramón y Cajal ('11) described it under the name "noyau de la voie optique bigeminale" for the cat. Le Gros Clark ('30) called it the large-celled nucleus of the optic tract in Tarsius.

Nuclear gray associated with lateral lemniscus (figs. 5 to 13). Probably the best and most logical way to describe the nuclei associated with lemniscus lateralis is from behind forward, since the lemniscus is an ascending path in the auditory system. In rodents the lateral lemniscus is more ventrolateral than in primates in which the increased pontine gray and fibers push the lemniscus dorsalward. Rodents as a group have keen hearing and well developed internal 
ears. It is to be expected, then, that the primary auditory system should show a comparable degree of differentiation.

In this series the mouse shows the simplest pattern. At the level of the dorsal tegmental nucleus in the upper pons, a group of large and small cells lies in the lateral angle of the fourth ventricle immediately below the cerebellum and dorsal to a large mass of small cells which constitute the marginal nueleus of the superior cerebellar peduncle. These cells represent, in part, the nucleus isthmi which has a similar location in reptiles. (For a complete discussion of the phylogeny of nucleus isthmi see Ariëns Kappers, Huber and Crosby, 36.) In mammals it is called nucleus dorsalis lemnisci lateralis, and it does not correspond to the nucleus dorsalis lemnisci lateralis of the Winkler and Potter ('11) figures 21 through 24. In the mouse this nuclear group shifts lateralward (always keeping medial to the lemniscus) as the inferior colliculus and cuneiform area ride in overhead (figs. 9, 10). The dorsal nucleus becomes separate from the nucleus of the superior cerebellar peduncle, but, as the cuneiform area increases in size, the larger cells of the dorsal nucleus can be traced for some distance rostralward, partly mingled in the inferior border of the cuneiform area. The small cells do not extend forward into this region. Scattered neurons belonging to the ventral nucleus of the lateral lemniscus extend upward to meet the dorsal nucleus and the cuneiform area.

In the course of the lemniseus itself a very large group of neurons are to be found in the mouse. These make up the caudal portion of the ventral nucleus of the lateral lemniseus (nucleus caudalis ventralis pars ventromedialis, see figs. 7 and 8 for rat) as the tract swings up into the inferior colliculus. This caudal group of cells is more in the nature of an interfascicular nucleus than any well-defined nuclear mass. More rostrally at the cephalic pole of the inferior colliculus the rostral division of the ventral nucleus (nucleus rostralis ventralis) lies on the lateral edge of the brain stem lateral to the fibers which run forward as the peduncle of the inferior coliiculus to the medial geniculate nucleus. This rostral ventral nucleus (rat, figs. 5, 6) drops out just caudal to the medial geniculate nucleus. It is a welldefined eliptical group of medium-sized, oval, multipolar neurons which stain lightly; the cell nucleus is large and pale. The caudal ventral nucleus is composed in part of small and medium-sized, multipolar neurons of the efferent type that stain deeply with toluidin blue; the rest of the cells are like those of the more rostral ventral nucleus.

The rat shows essentially the same pattern of lemnisci nuclei as those described above for the mouse. The dorsal nucleus (figs. 7, 8) of the lateral lemniseus is less well delimited perhaps, and the anterior 
continuation of these cells is somewhat more difficult to pick out because they are scattered. They are medium-sized, oval and round cells, together with some small ones, which take a medium stain. On the whole they are in type much like those of the rostral ventral nucleus. The caudal rentral nucleus (figs. 6 to 8 ) has a denser cell population than that in the mouse, and considerably more of the large and medium multipolar neurons of the motor variety are present. The ventral nucleus and the cuneiform area are similar in the rat and the mouse.

By analogy the very large ears of the rabbit should indicate especially acute hearing. Certainly if the lemniscal nuclei and the configuration of the medial geniculate nucleus are an indication of keen auditory powers, the rabbit is better equipped than either the rat or the mouse.

The basic pattern of lemniscal nuclei is present in the rabbit. Nucleus dorsalis lemnisci lateralis (figs. 11, 12) is found in the same position with similar relationships as in the other rodents. The cells are relatively few and are of the oval multipolar type with a large pale nucleus. The cuneiform area is very large both in cross sectional and rostrocaudal extent. The larger cells of nucleus dorsalis lemnisci lateralis which continue forward encroach upon the ventrolateral edge of the cuneiform area. This nucleus like the principal nucleus of the inferior colliculus is composed of small and medium-sized fusiform neurons.

Nucleus caudalis ventralis lemnisci lateralis is not only very large in the rabbit but it shows several subdivisions. Curiously enough the chief nucleus of the inferior colliculus is not so large proportionately as the cuneiform area and the caudal ventral nucleus. In most caudal planes the latter nucleus is composed of scattered, interfascicular cells as in the mouse and rat. More rostrally this ventromedial division of the nucleus (figs. 11 to 13) is more compact and comma-shaped, with the head composed of medium and large motor-type neurons. The tail contains more of the medium-sized motor type and oval to round neurons. Laterally, along the outer wall of the brain stem, a band of medium-sized, paler, oval cells is formed; this is the lateral division (fig. 12). Simultaneously with the appearance of the inferior colliculus in the sections, a group of the pale oval cells are seen just below it on the lateral wall. There is a band of cells which connects this caudodorsal division (figs. 11, 12) with the chief nucleus of the inferior colliculus. The caudodorsal division is not large and is well circumseribed, but it is soon replaced by larger cells, mostly of the motor type, which form the rostrodorsal division (fig. 13). This last division extends dorsalward and forward along 
the ventrolateral border of the inferior collicular nucleus for a considerable distance. In addition to these definite nuclear groups, there is an increased number of very large motor-type neurons in the eapsular nucleus of the inferior colliculus, particularly at the ventral pole.

The rostral ventral nucleus (fig. 13) in the rabbit is large, and it replaces the lateral division of the caudal ventral nucleus. As in the other rodents the rostral ventral nucleus is related to the peduncle of the inferior colliculus and it extends forward to the medial geniculate nucleus.

Winkler and Potter ('11) have figured some of these nuclei of the lateral lemniscus, but the divisions and names differ from those used in this paper. As nearly as can be determined from the plates, their ventral nucleus of the lateral lemniscus (Winkler and Potter, '11, fig. 25) is equivalent to the most caudal part of our ventromedial division. Their dorsal nucleus of the lateral lemniscus (Winkler and Potter, figs. 21 to 24 ) corresponds to the caudodorsal and the rostrodorsal divisions of our caudal ventral nucleus and in part to our rostral ventral nucleus, and their nucleus lateralis lemnisci lateralis (Winkler and Potter, fig. 23) is part of our nucleus rostralis ventralis. (Compare with figs. 5-13.)

In connection with the highly differentiated lemniscal nuclei note should be made here that the medial geniculate body also shows specialization. Usually there is a principal or central nucleus surrounded by an external capsule of cells which may or may not be divisible into a dorsal and a ventral subgroup. In the rabbit the dorsal group of capsular cells lies in a well-defined and separate oval mass on the dorsal aspect of the central nucleus (fig. 14). The cells are of the same type as those of the rest of the medial geniculate nuclei : medium-sized, multipolar neurons with a large pale nucleus, which stain rather deeply. Winkler and Potter ('11) figured this nueleus as $b$ of the medial geniculate complex, and Kuhlenbeck and Miller ('42) described it as the dorsal magnocellular division of nucleus geniculatus medialis dorsalis. The significance of these nuclei can only be determined after a study of their connections.

\section{MIDLINE NUCLEAR GROUPS}

\section{Linear nuclear gray}

Throughout the midbrain a series of nuclear groups occurs in the midline, interrupted by the several decussations which are in the mesencephalon. Castaldi ('23) has allocated these groups to three divisions and called them pars caudalis, pars medialis, and pars 
rostralis of nucleus linearis respectively. The cells are small and medium-sized, elongated neurons which do not stain very deeply. The cell nucleus is large with a prominent eccentric nucleolus. The posterodorsal cells are more numerous and slightly more deeply stained.

Pars caudalis is the largest group (fig. 5) in the rodents studied. It is first seen, approaching it from the posterior end, as a spray of cells extending downward from a position between the two medial longitudinal fasciculi to the dorsal fibers of the superior cerebellar decussation. As the fibers of this latter thin out, the cells spread toward the interpeduncular nucleus and forward beyond the caudal pole of the red nucleus for a short distance. Caudal to the ventral extension of this caudal part of the linear nucleus, a larger, more deeply staining group of cells lies above nucleus interpeduncularis and extends back to the pontine region. This group is the median nucleus of the pontine raphé, and it does not belong in the linear complex.

At planes through the anterior third-quarter of the red nucleus, the middle group of linear cells (fig. 4) lies above the dorsal tegmental decussation and between the lower portion of the two medial longitudinal fasciculi. The cells are few in number, but otherwise they resemble those of the rest of the nucleus. The rostral group, which is also sparsely populated, is found at the anterior pole of the red nucleus and perhaps slightly beyond. It lies somewhat more rostral and more ventral than nucleus medianus anterior between the two interstitial nuclei (fig. 2).

\section{Interstitial nucleus of the commissure of Forel (supramammillary decussation) ( fig. 2)}

The cells of this nucleus are intermingled with the decussating fibers of the commissure. A few neurons extend across the midline, more are grouped on either side. They begin at about the middle of the mammillary body rostrally and extend caudalward to the posterior part of it. The nucleus is not a conspicuous one; it is probably best developed in the rat and relatively smallest in the rabbit. The cells are diffuse and may extend lateralward to substantia nigra. They are small, granular and stellate neurons, which stain lightly and have a large indefinite nucleus and a large nucleolus.

\section{Nucleus of the decussation of Forel (ventral tegmental decussation) (figs. 3, 4)}

This nucleus is found at the level of the red nucleus and ventromedial to it. Since this decussation overlies the caudal part of the mammillary body and the rostral portion of nucleus interpeduncularis 
in the smaller brains of the mouse and the rat, the nucleus may be found scattered among the crossing fibers and dorsolateral to these structures. The neurons may extend lateralward as far as the red nucleus and caudalward to planes just behind the emerging roots of the oculomotor nerve. In the rabbit the nucleus begins a little more posteriorly at about the middle of the red nucleus. The mediumsized stellate cells stain lightly but make up a fairly compact nuclear group.

\section{Gray associated with ansulate commissure}

Immediately ventral and caudal to the ventral tegmental decussation, a crossing of various tectal and tegmental fibers takes place which is known as the ansulate commissure. Associated with this commissure in the rabbit is a band of small, stellate neurons, forming a crescent over the interpeduncular nucleus, which constitutes the nucleus of the ansulate commissure. These cells extend caudalward to the decussation of the superior cerebellar peduncle. In the rat and the mouse, the cells tend to form two groups immediately lateral to the posterior linear nucleus and overlying the dorsolateral surface of the interpeduncular nucleus.

\section{Interpeduncular nucleus (figs. 4 to 6)}

This nucleus is an unpaired, midline cell mass lying just above the interpeduncular fossa and forming an eminence on the surface. The cerebral and mammillary peduncles are on either side of it. The decussation of Forel (ventral tegmental decussation) is dorsal to the rostral portion of the nucleus, and the decussation of the superior cerebellar peduncle lies dorsal to it posteriorly. Nucleus interpeduncularis extends from the caudal end of the mammillary body back to the ventral pontine nuclei. Its greatest size is reached at levels just behind the emergence of the oculomotor nerve.

In the rat the nucleus resembles an inverted cone, the cells being thickest in the upper central part of the nucleus and sparser in the wider peripheral zone. The neurons for the most part are the small granular type, fairly deep staining, in which the nuclear structures are hard to differentiate. In the peripheral zone a few small multipolar cells can be seen; these increase in number at the lower end of the nucleus. Toward the caudal levels, small and medium-sized, deep-staining multipolar neurons make up the small (dorsal) end of the cone.

This nucleus in the mouse and rabbit has more nearly the shape of a beehive and a somewhat different, arrangement of its cellular elements. Except for a small knot of cells that is separated from the 
main nucleus by the fibrous capsule, the mouse interpeduncular nucleus is a fairly uniform mass of small round and oval cells. These small neurons are very compact dorsally and extend back to the pontine gray. A few larger, stellate cells are to be found in the ventral zone and along the lateral edges.

The small-celled element in nucleus interpeduncularis of the rabbit resembles a biconcave lens, being large rostrally and caudally and more slender in the middle. Lateral groups of medium-sized, multipolar cells lie on either side in the concavities and are very conspicuous distinct groups in the midregion. A small, very deeply staining mass of multipolar cells makes an appearance dorsally for a short distance at about half-way through the interpeduneular nucleus. Caudally the nucleus is more uniform with the larger multipolar cells seattered on the ventral and lateral borders.

Ramón y Cajal ('11) has given a detailed description of the cells of the interpeduncular nucleus, and it has been described many times for mammals since the early descriptions of Henle (1871), Forel (1877), and von Gudden (1881). The nucleus is probably as well developed in rodents as in any of the mammals and it shows the greatest differentiation in the rabbit.

\section{BASAL MIDBRAIN GRAY}

\section{Substantia nigra}

This cellular mass, together with the cerebral peduncle, oceupies the basis peduneuli of the midbrain. It extends from the subthalamus of the diencephalon (from a plane through the anterior third of the mammillary body in the rat) eaudalward to inferior collicular levels in the region of the trochlear nucleus. Three regions can be differentiated by the size and grouping of the neurons and by their staining reactions.

Zona reticulata (figs. 1 to 5,14 ) is characterized in all three of the rodents studied by medium-sized, deep-staining cells in the upper (dorsal) portion of the peduncular fiber bundles. The area presents a typical reticular appearance with the long dendrites of the widely seattered cells forming a loose network. The cytoplasm of these motor-type neurons stains deeply because of the large, irregular Nissl granules. The cell nucleus is somewhat paler with a large and prominent nucleolus. Zona reticulata has a more rostral extent than either zona compacta or pars lateralis and reaches its maximum size at levels through the red nucleus and the oculomotor complex. In the mouse and the rabbit this zone disappears at about the mid-mesencephalic region, some distance rostral to the pontine gray. 
Zona compacta (figs. 2 to 5,14 ) is made up of larger (smaller in the mouse) cells than those of zona reticulata, and they tend to be more elongated and more deeply stained. The zone begins over the medial tip of the cerebral peduncle, dorsal to zona reticulata, and gradually extends dorsolateralward to form rostrally a conspicuous band over the medial half of the peduncle. In the mouse and the rabbit, zona compacta has the most caudal extent of the three divisions, ending at the upper border of the pons. In its rostral portion, this zona is primarily an eliptical band of neurons with an occasional accumulation in the rat of more cells at the medial tip. However, there are two interruptions in the course of the nucleus, the first being the nucleus of the basal optic root in the region of the caudal end of the mammillary body. The compact area may be reduced to only a few cells medially and laterally at this place. The emerging roots of the oculomotor nerve cut across the medial end of zona compacta more caudally and break it up into larger or smaller patches of deep-staining cells.

Just behind the beginning of zona compacta rostrally, the most dorsolateral cells in zona reticulata seem to collect into a more compact group, pars lateralis (figs. 2 to 4,14 ), which attains some size and extends almost to the caudal end of the cerebral peduncle. The cells are of the larger type found in substantia nigra and stain very deeply. At more rostral levels, pars lateralis seems to be connected by a string of seattered neurons to zona reticulata, but at caudal levels it occupies a midpeduncular position and eventually fuses with zona compacta. Pars lateralis has a larger rostrocaudal dimension in the rat than in the other two rodents studied.

Substantia nigra has been described by Ramón y Cajal ('11) as having only two parts in cat and rabbit: an inferior and a superior zone. Likewise, Foix and Nicolesco ('25) gave a description of only two regions for man, dog, sheep and rabbit; there is no evidence in our rodent material of their special groupings in zona compacta. Rioch ('29 b) has given a full account of three divisions of substantia nigra in the eat.

Zona reticulata is large in rodents, though it is somewhat reduced in the rabbit as compared to the rat. Zona compacta is a fairly narrow, distinct band of cells, and there is no evidence of pigment in any part of substantia nigra.

\section{Nucleus of basal optio root (figs. 3,4 )}

In the rat and the mouse, this nucleus lies caudal to nucleus subthalamicus, medial to the cerebral peduncle, and lateral to the caudal portion of the mammillary body. It is slightly more caudal in the rabbit, lying behind the mammillary body and extending to the 
rostral rootlets of the oculomotor nerve. In the mouse, the oculomotor roots cut the caudal portion of the nucleus. The cells form an oval or eliptical mass, which lies across the medial portion of zona compacta of substantia nigra. The neurons are medium-sized and small, elongated, multipolar cells. They stain deeply and have a long, large, pale nucleus with a prominent nucleolus. In some cases the nucleus of the basal optic root is so closely related to substantia nigra, both spatially and in cell type, that it can be differentiated only by the entering basal optic root and by the grouping of the neurons. An extensive comparative study of this nucleus and its connections has been made by Gillilan ('41) and should be consulted for the pertinent literature.

\section{DISCUSSION AND SUMMARY}

One of the regions of mystery of the brain has been the mesencephalon. To be sure, a few of the more conspicuous structures such as the red nucleus and the eye-muscle nuclei have had considerable attention, but there are vast regions such as nucleus lateralis profundus and substantia nigra about which practically nothing is known. The literature on the midbrain is not plentiful, and most of these descriptions are sorrowfully inadequate. The most complete study is that of Castaldi, to whose work frequent reference has been made throughout this paper. In the light of comparative neurology, certain structures in the midbrain of rodents are worthy of discussion.

The pretectal region, including nucleus pretectalis and the large-celled nucleus of the optic tract, falls in the diencephalo-mesencephalic transition zone in rodents. For the most part the nuclei of this region are not well demarcated, although together they are large in size. The most obvious fiber bundle associated with the pretectal nucleus is the optic tract.

The nuclei of the posterior commissure and the medial longitudinal fasciculus can be considered as a group, since the medial longitudinal fasciculus so closely relates them all. The several differentiated masses associated with the posterior commissure are the most rostral structures and 
seem to be related cytologically to the central gray. The interstitial nucleus of the medial longitudinal fasciculus and its caudal counterpart, the annular nucleus of the fasciculus, are reticular elements in and about this fiber bundle and their cells are like those of nucleus lateralis profundus mesencephali. Thus the medial longitudinal fasciculus has an interstitial nuclear group and terminal nuclear groups which include the motor nuclei of the brain stem as well as the commissural nuclei associated with it (figs. 1 to $5,13,14$ ).

The nerves supplying all the eye-muscles except the lateral rectus have their cells of origin in the mesencephalon in the gray below the aqueduct. It is obvious to all observers that these nuclei are derivatives of the ventral nucleus of the central gray. The oculomotor nucleus has only a dorsolateral and a ventromedial division, although in the rabbit the dorsolateral portion shows some subgrouping. The trochlear nucleus is continuous, or very nearly so, with the oculomotor nucleus in all rodents. The accessory trochlear nucleus seems to be variable both within the species and the genus, but when it is present it lies usually on the left side a considerable distance behind the principal nucleus. The Edinger-Westphal nucleus is incompletely separated into a paired structure in rodents. The rostral Edinger-Westphal nucleus is distinct from the caudal Edinger-Westphal nucleus, but its relation to the latter has yet to be settled.

Very little can be said at this time about nucleus medialis profundus, nucleus dorsalis tegmenti and nucleus laterodorsalis tegmenti because their fiber connections have not yet been studied. The relation of the various central nuclear groups to the central gray has been mentioned previously in this report, and nothing further can be added just now. Likewise any discussion of the nucleus of the mesencephalic root of the trigeminal nerve is not justified until a thorough study has been made for all mammals and the results correlated.

One of the most interesting findings in the rodent mesencephalon is the development of the nuclei associated with the 
central auditory pathways. The size and differentiation of the caudal ventral nucleus of the lateral lemniscus is significant. On the basis of cell types this nucleus probably serves two functions: the round and oval cells indicate that it is a region for relaying impulses to higher centers, chiefly the inferior colliculus and the medial geniculate nucleus. The motor-type cells occurring in increasingly large numbers suggest that impulses are sent to lower brain and cord centers, probably in reflex arcs. The dorsal nucleus of the lateral lemniscus is definitely on the wane in mammals. The cuneiform area will be discussed in a later paper when its connections are better known.

The various psychological studies made on rats, mice and guinea pigs with reference to response to tonal stimuli have not been entirely successful. It is suggested here that the fault does not lie in the auditory mechanism of these animals, but in the cortical centers which must interpret and associate tone with other activities. It is an anatomical fact that the brain-stem structures of lower mammals are often as good as or better than those found in man, but the cortical centers are decidedly inferior. Behavior and learning patterns in the lower animals, then, cannot be judged by criteria set by the abilities of primates and man.

The large number of scattered cells which make up nucleus lateralis profundus mesencephali suggest its significance as a correlation center for the great variety of impulses that pass over the fibers among which these cells lie. In the course of phylogeny certain of these cells have been aggregated into definite groups related to specific functions. The red nucleus is the outstanding example of this; the magnocellular portion of the red nucleus is concerned with relaying impulses from the dentate nucleus of the cerebellum to lower centers. The number of large cells in the red nucleus seems to depend upon the number of cells which through neurobiotactic influences come to lie more caudally along the superior cerebellar peduncle. In rodents pars magnocellularis is still the largest part of nucleus ruber. The small cells which make up the 
more rostral part of the nucleus are concerned with transmitting impulses forward, and the size of the parvocellular portion, therefore, is directly related to the development of the dorsal thalamus and the cerebral cortex. Pars parvocellularis is relatively small in rodents, and particularly so in the rabbit.

Nucleus interpeduncularis is an olfacto-visceral correlation center receiving connections from the telencephalic olfactory areas, the mammillary body, the habenula, and bulbar visceral centers by way of the mammillary peduncle. It discharges to the dorsal tegmental nucleus and to other lower centers through the dorsal longitudinal fasciculus and the pedunculotegmental tract. The large size, the degree of differentiation of the cells making up the mass, and the subdivisions of nucleus interpeduncularis in rodents lead us to believe that our knowledge of this nucleus will be greatly augmented as further fiber connections are thoroughly studied.

The nuclear groups of basis pedunculi have their origin in a common undifferentiated gray, and therefore the similar cell types and interconnections of substantia nigra, nucleus tractus optici basalis, and the interstitial nucleus of the mammillary peduncle are not surprising. Zona reticulata and pars lateralis of substantia nigra are larger in rodents than zona compacta, which is better developed in primates.

The dorsal nucleus of the raphé is a very elaborate and conspicuous structure in the lower mesencephalon of rodents. It is a derivative of the ventral nucleus of the central gray, and other than that it is a commissural nucleus, nothing is known of its connections or function at present.

The mesencephalon of rodents is typically mammalian. Especially outstanding nuclear structures have been emphasized in both the description and discussion. The significance of the pattern found in rodents cannot be fully appreciated until the fiber studies are completed. 


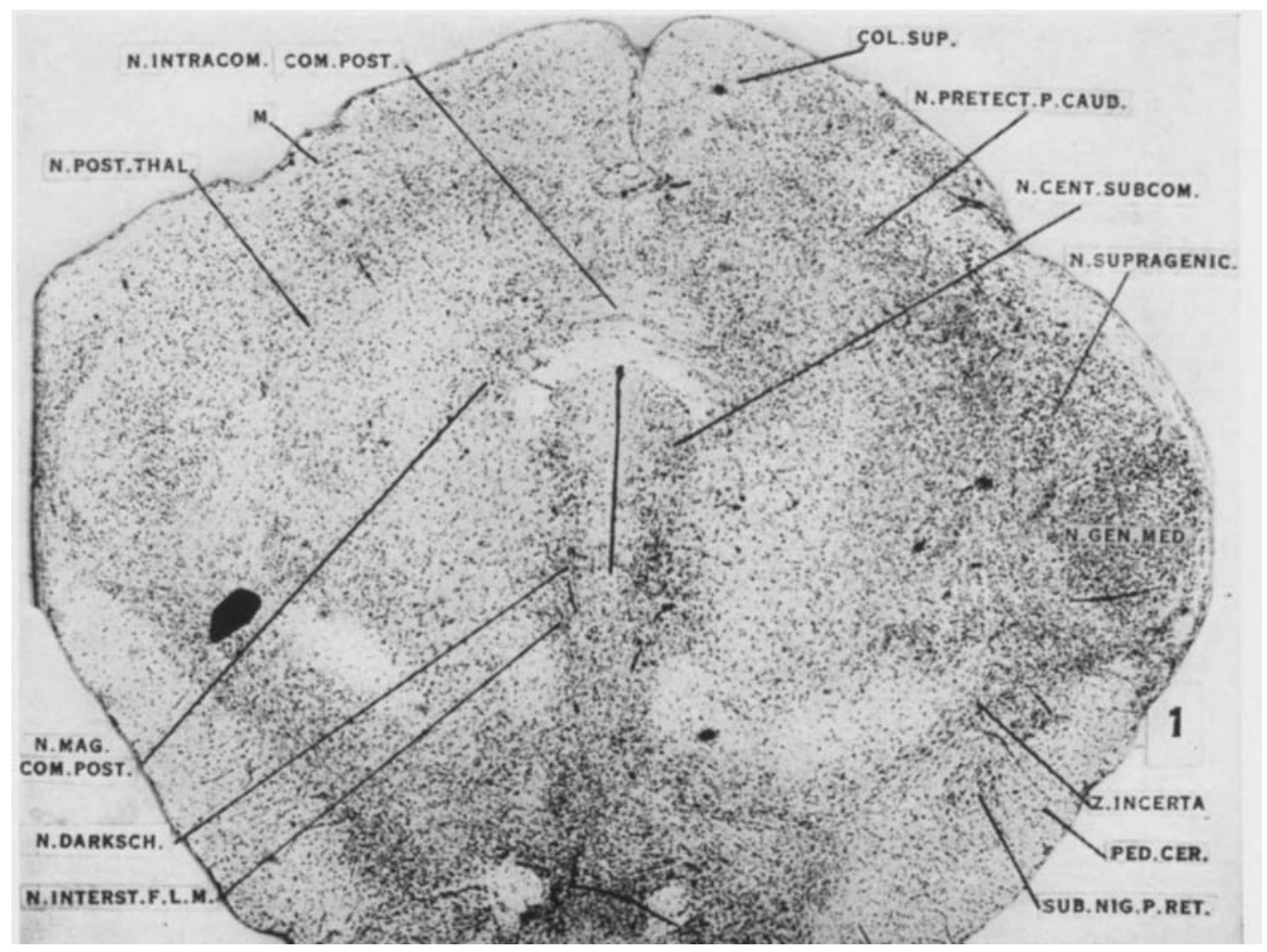

1 Rat brain section through the posterior commissure and rostral pole of the superior colliculus. Note in particular the relationships of nucleus pretectalis and of the nuclei associated with the posterior commissure. Toluidin blue. $\times \mathbf{2 0}$. 
PI.ATE 2

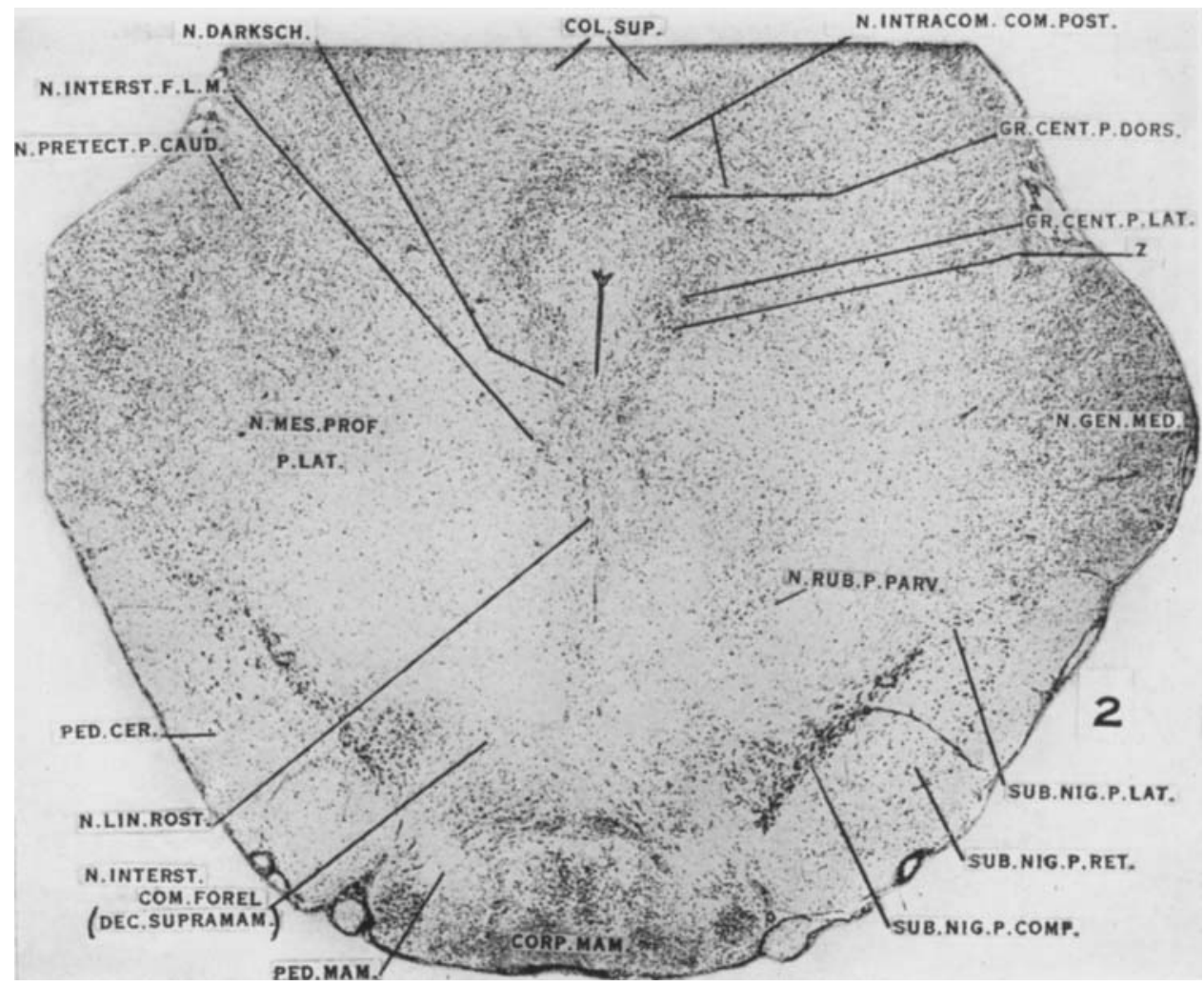

2 Rat brain section through the rostral pole of the midbrain. Toluidin blue. $\times 20$. 
PI.ATE 3

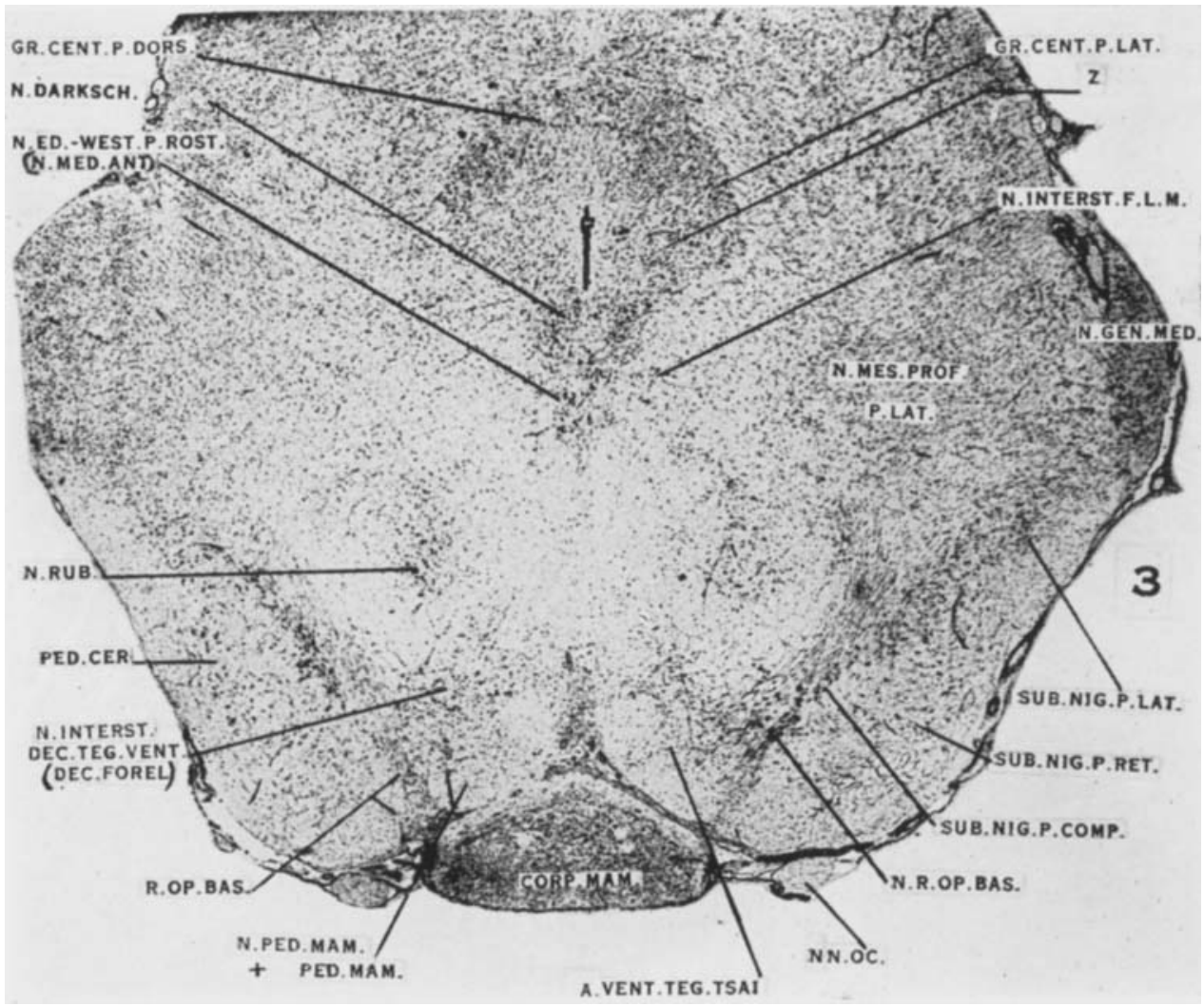

3 Rat brain section through the rostral Edinger-Westphal nucleus. At this level the red nucleus is composed of a mixture of small and medium-sized cells and oceasional large ones. Toluidin blue. $\times 20$. 
PLATE 4

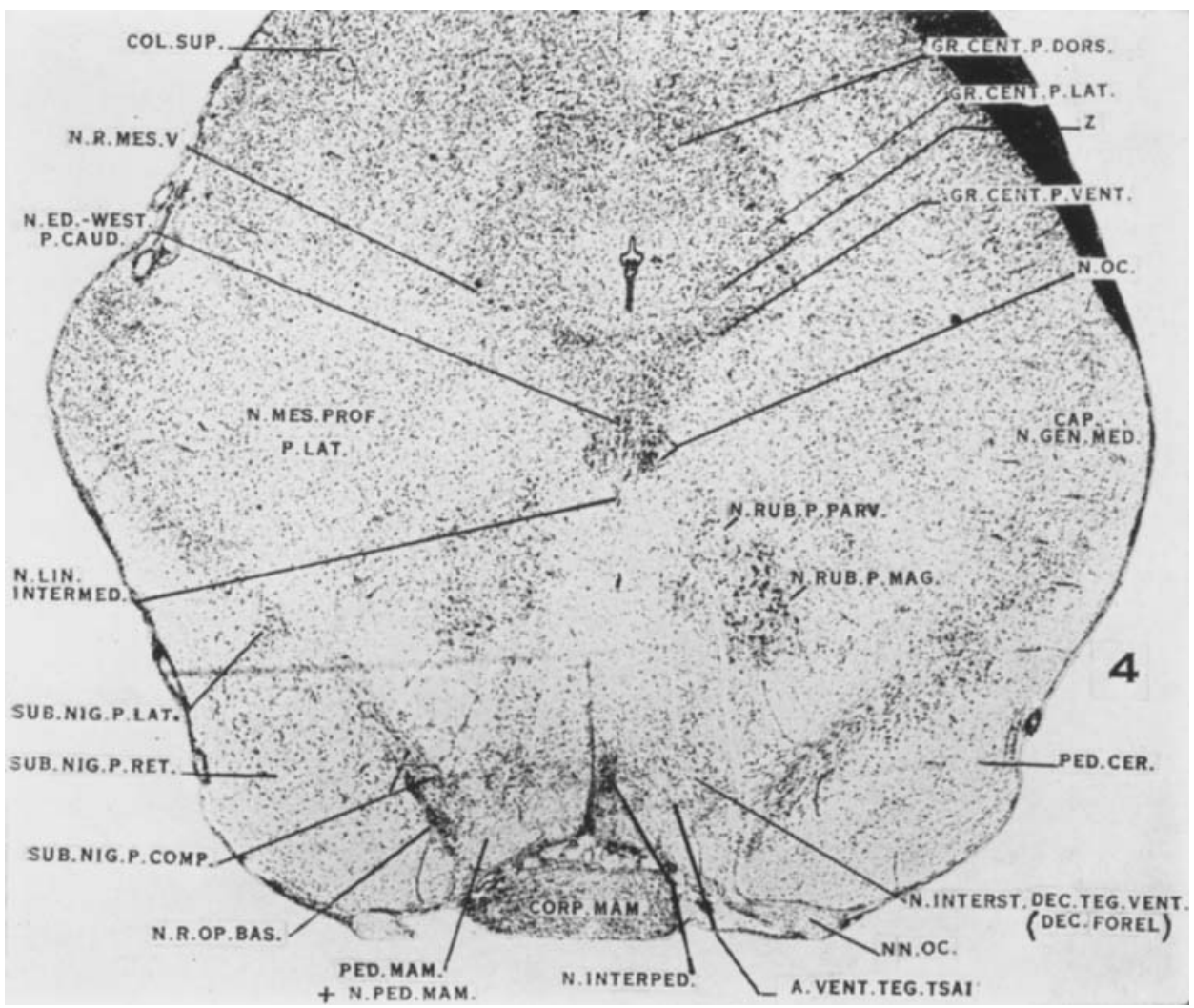

4 Rat brain section through the eaudal Edinger-Westphal nucleus and the rostral pole of oculomotor nucleus, which shows a dorsolateral and a ventromedial division. The magnocellular portion of the red nucleus has a cap of small cells at this level. Toluidin blue. $\times 20$. 
PLATE 5

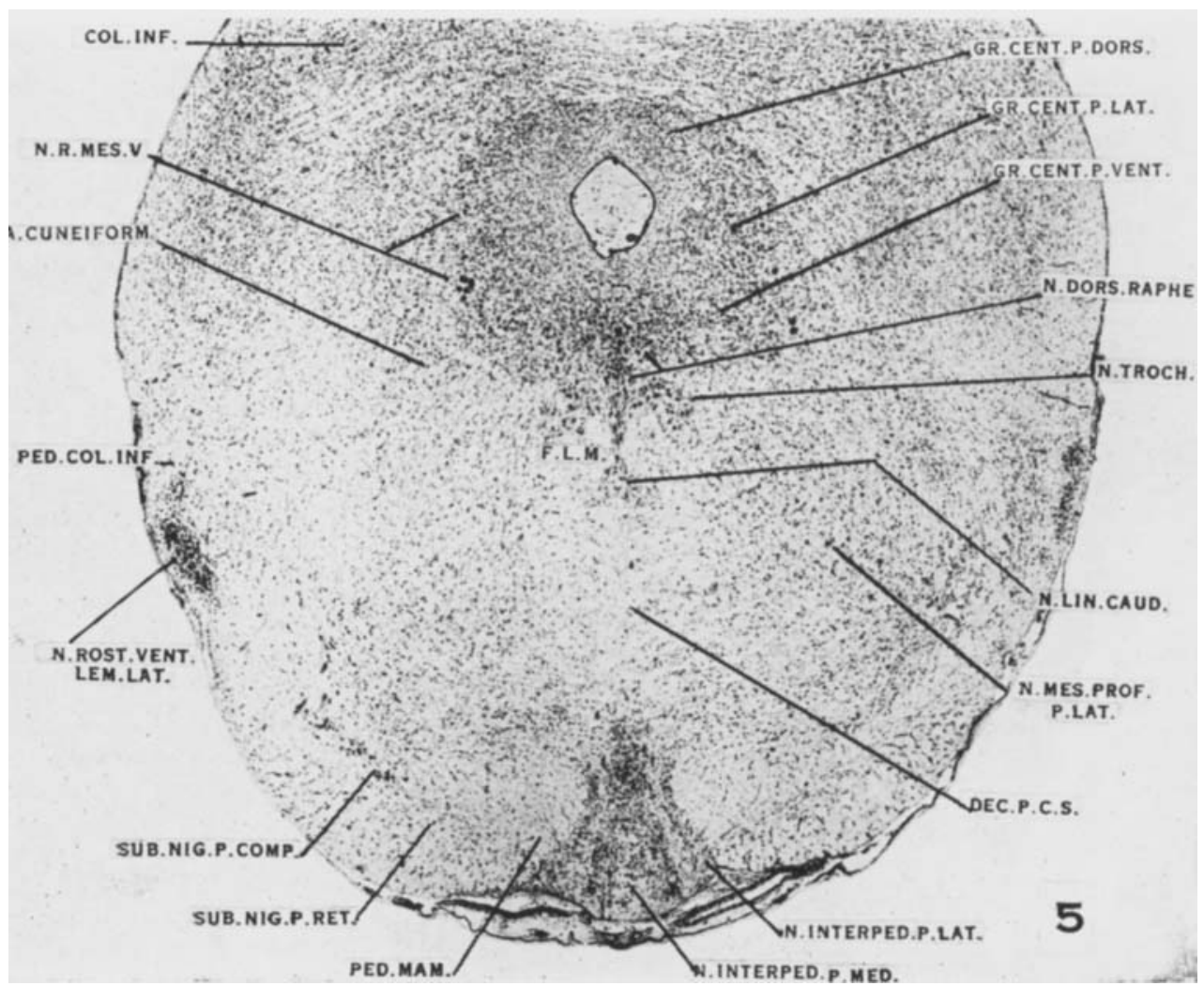

5 Rat brain section through the upper end of the inferior collieulus and the trochlear nueleus. The two divisions of nucleus interpeduncularis are especially well shown at this level, as is the rostral ventral nucleus of the lateral lemniseus. Toluidin blue. $\times 20$. 


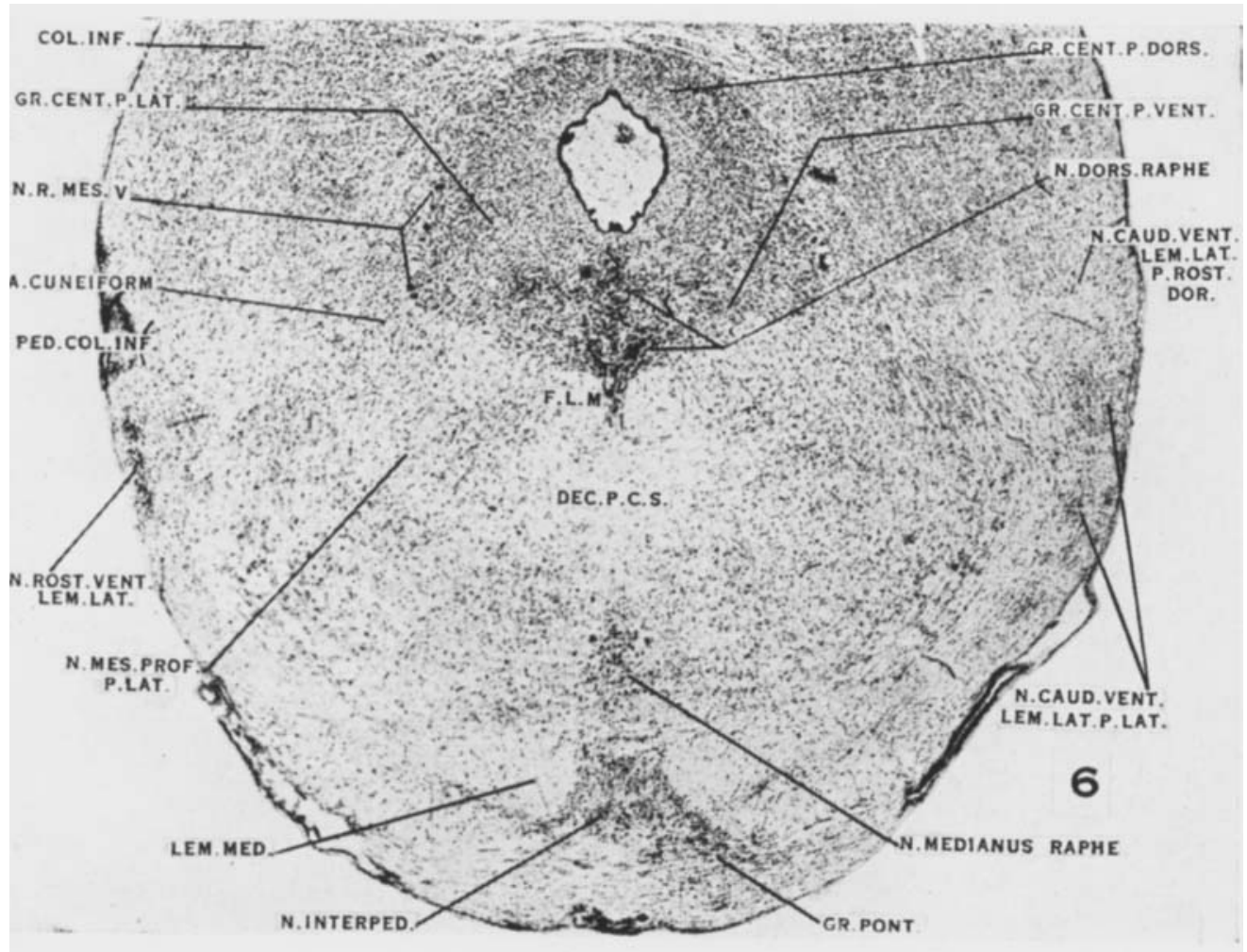

6 Rat brain section through the isthmus region, illustrating the dorsal nucleus of the raphé at its greatest development. Toluidin blue. $\times 20$. 


\section{PLATE 7}

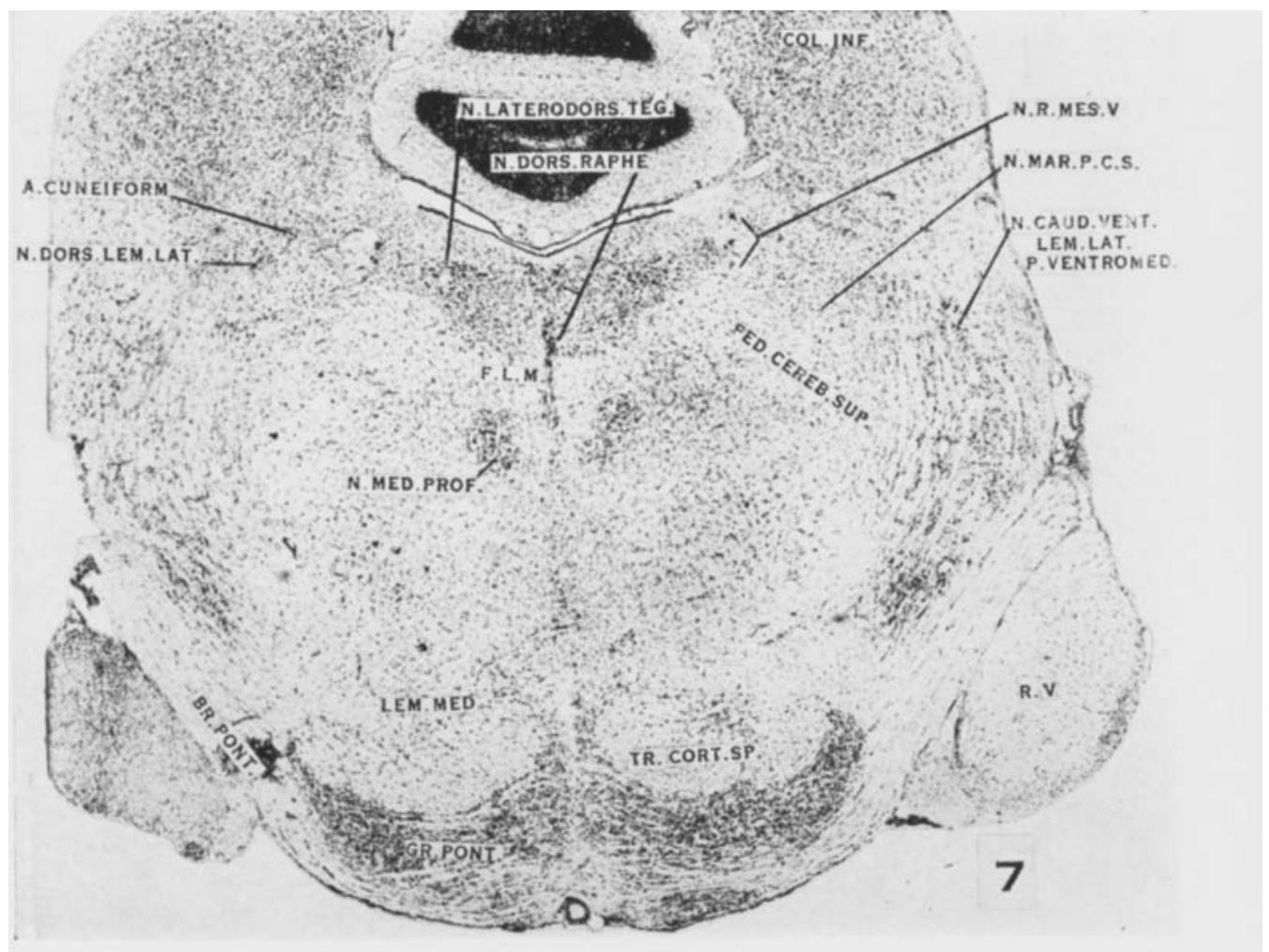

7 Rat brain section through the isthmus region just rostral to the dorsal tegmental nueleus and cutting through nucleus medialis profundus. The dorsal nucleus and the ventromedial portion of the caudal ventral nucleus of the lateral lemniscus can be seen. Toluidin blue. $\times 20$. 
PLATE 8

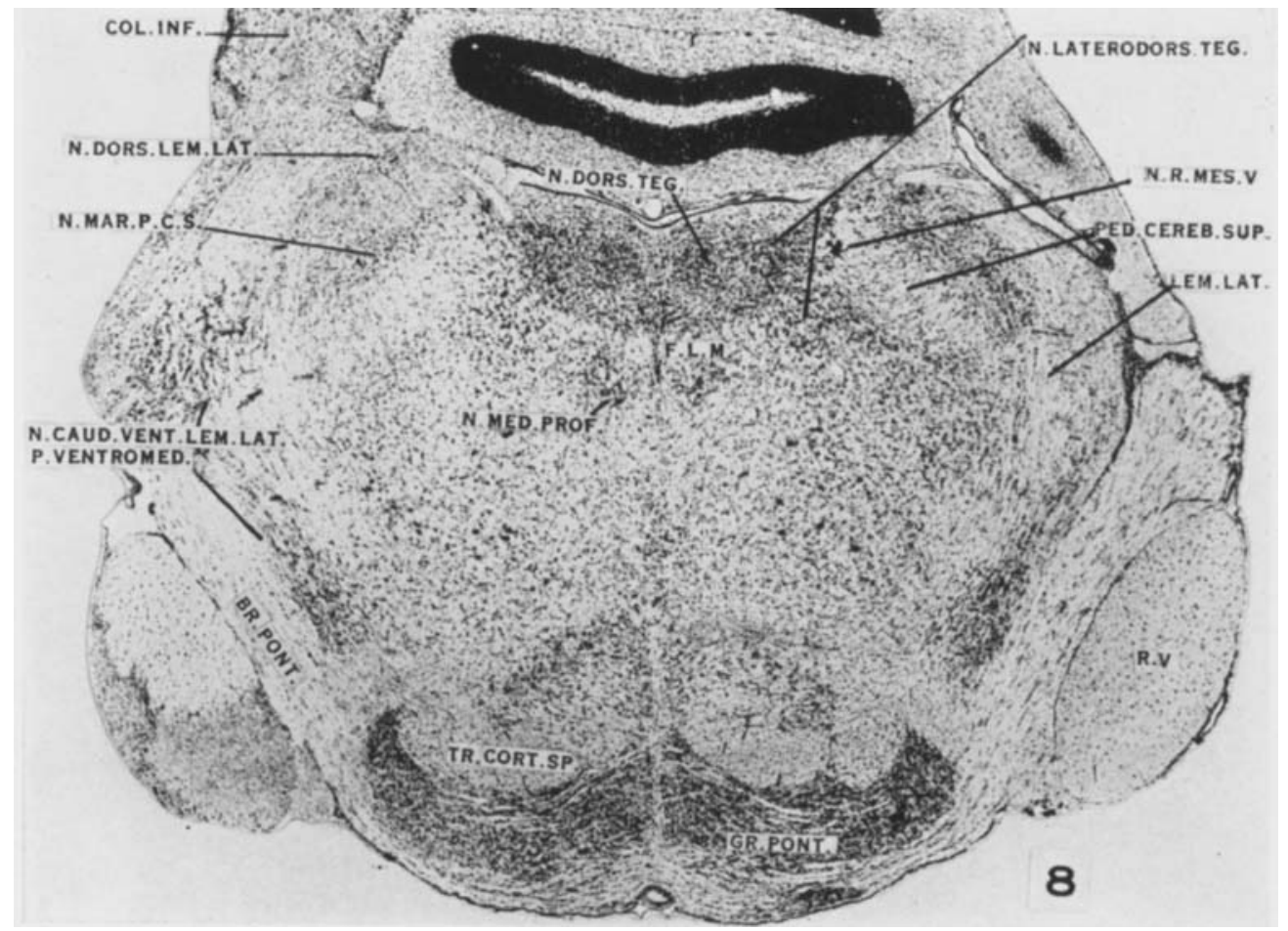

8 Rat brain section through the dorsal tegmental nucleus. Toluidin blue. $\times 20$. 


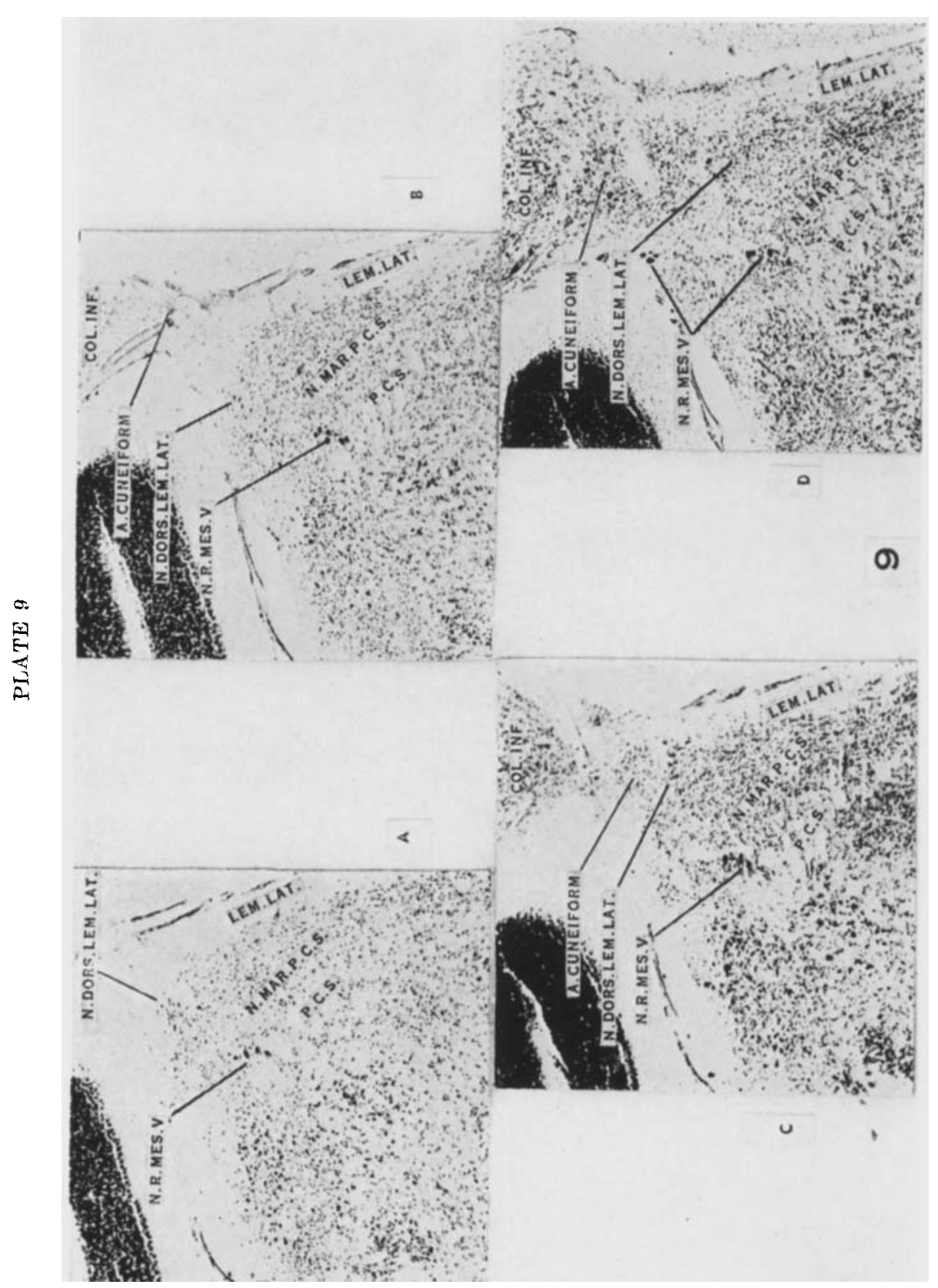

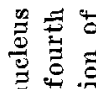

蛋

要要

के हैं

荢

ฐ .5

密

急

䊀

ॠ

$\cong 9$

대에

总苛

的

总营的

늘

冓

要

岁票完

高品

क

岁运

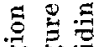
$\stackrel{丶 00}{\square}$

政

菩至

.

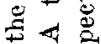

表实

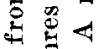

कs 200

可

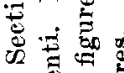

월 है

व $\$$

.

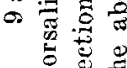




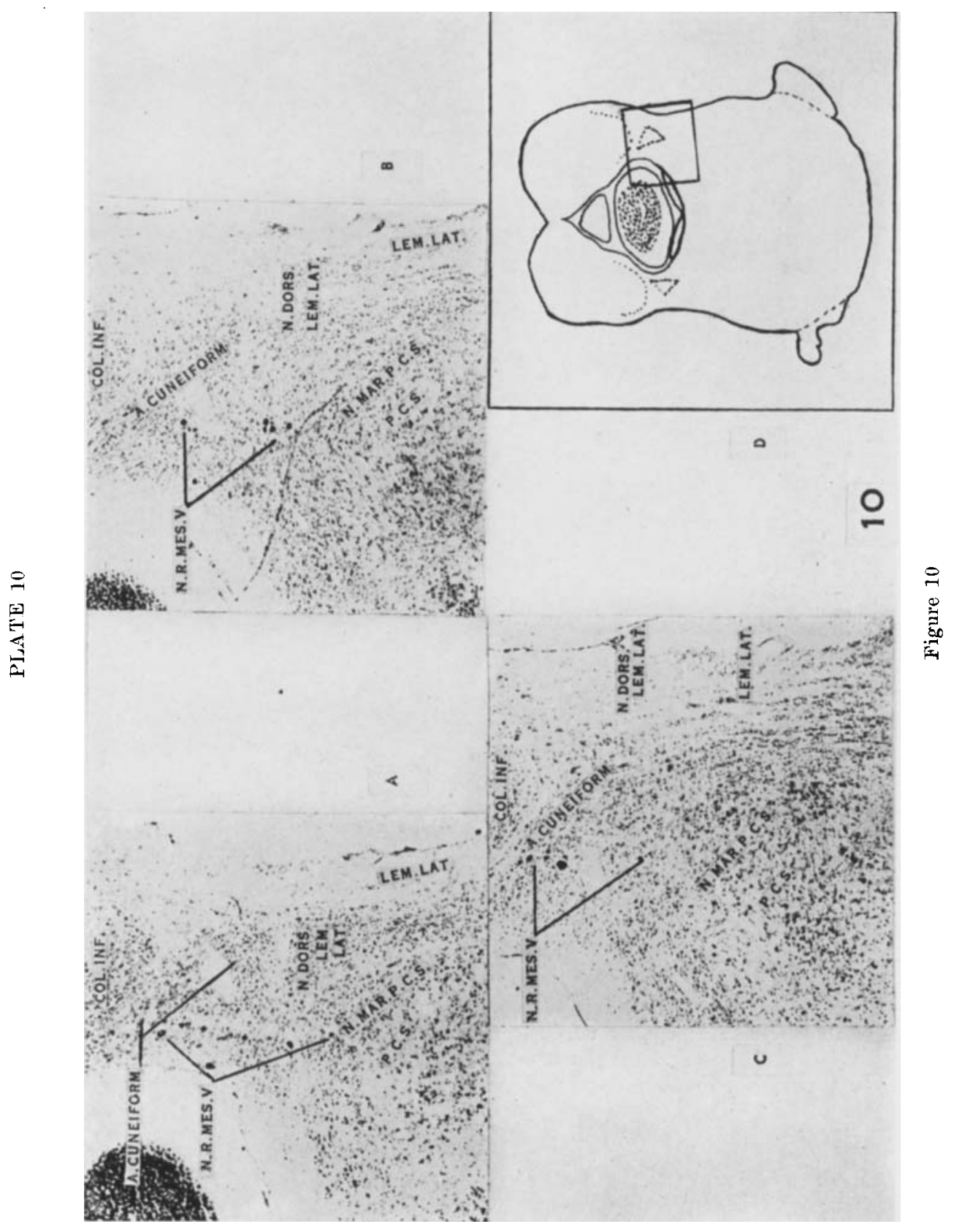




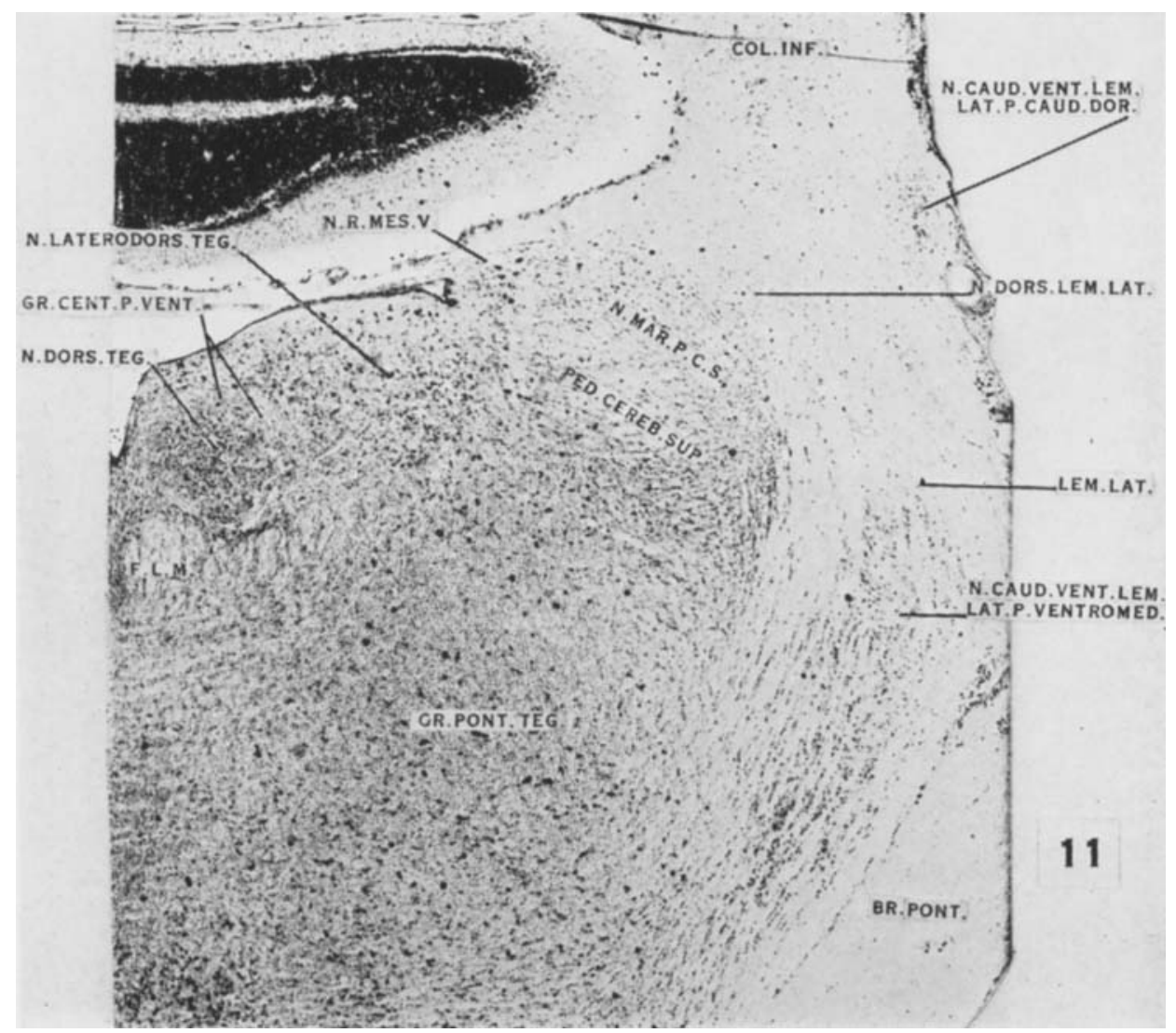

11 Rabbit section through the dorsal tegmental nucleus in the isthmus region. Those nuclei of the literal lemniseus appearing most caudally can be seen. Toluidin blue. $\times 20$. 


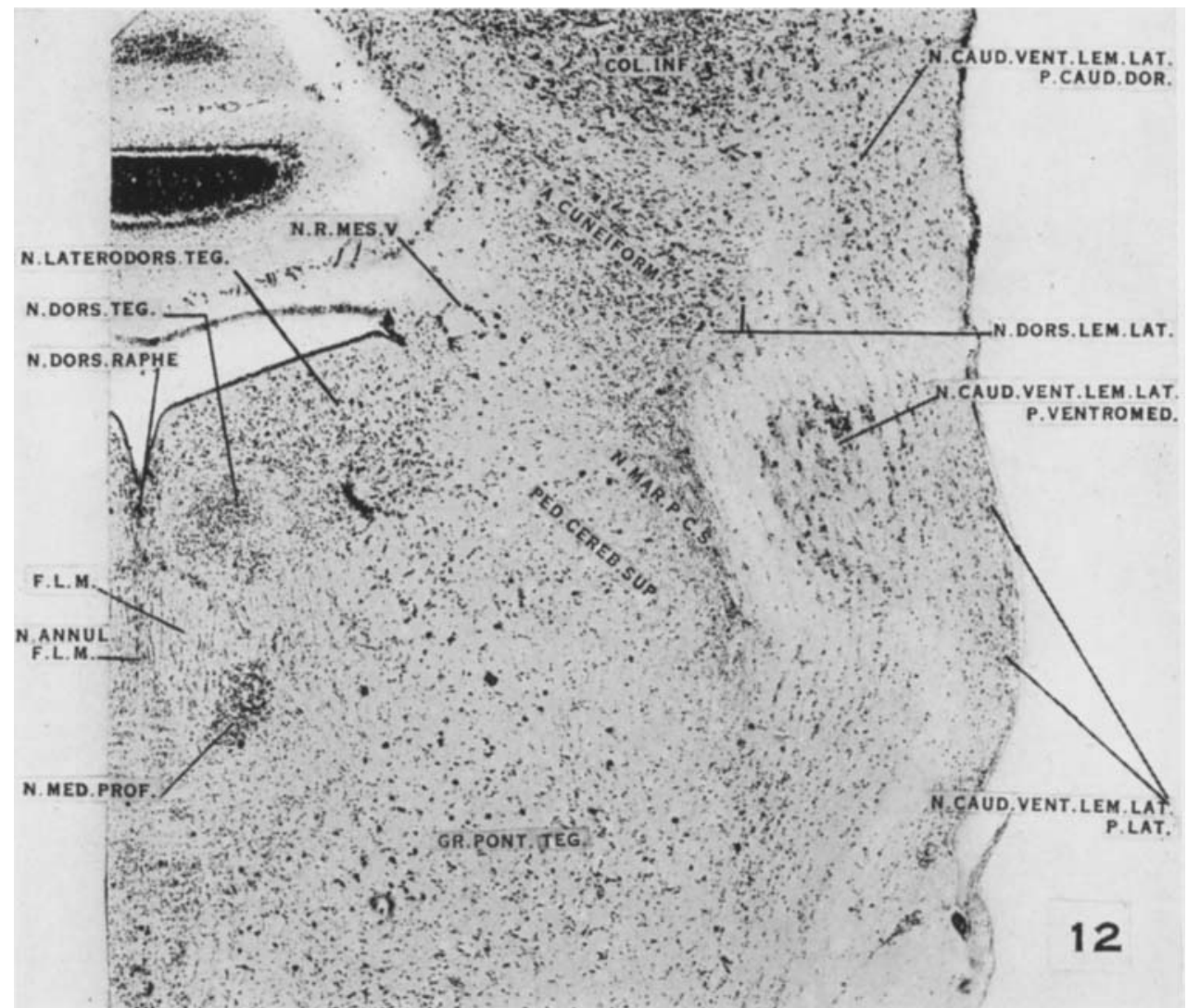

12 Rabbit brain through the rostral pole of nucleus dorsalis tegmenti and through nucleus medialis profundus. Note nuclei associated with the lateral lemniscus. Toluidin blue. $\times 20$. 


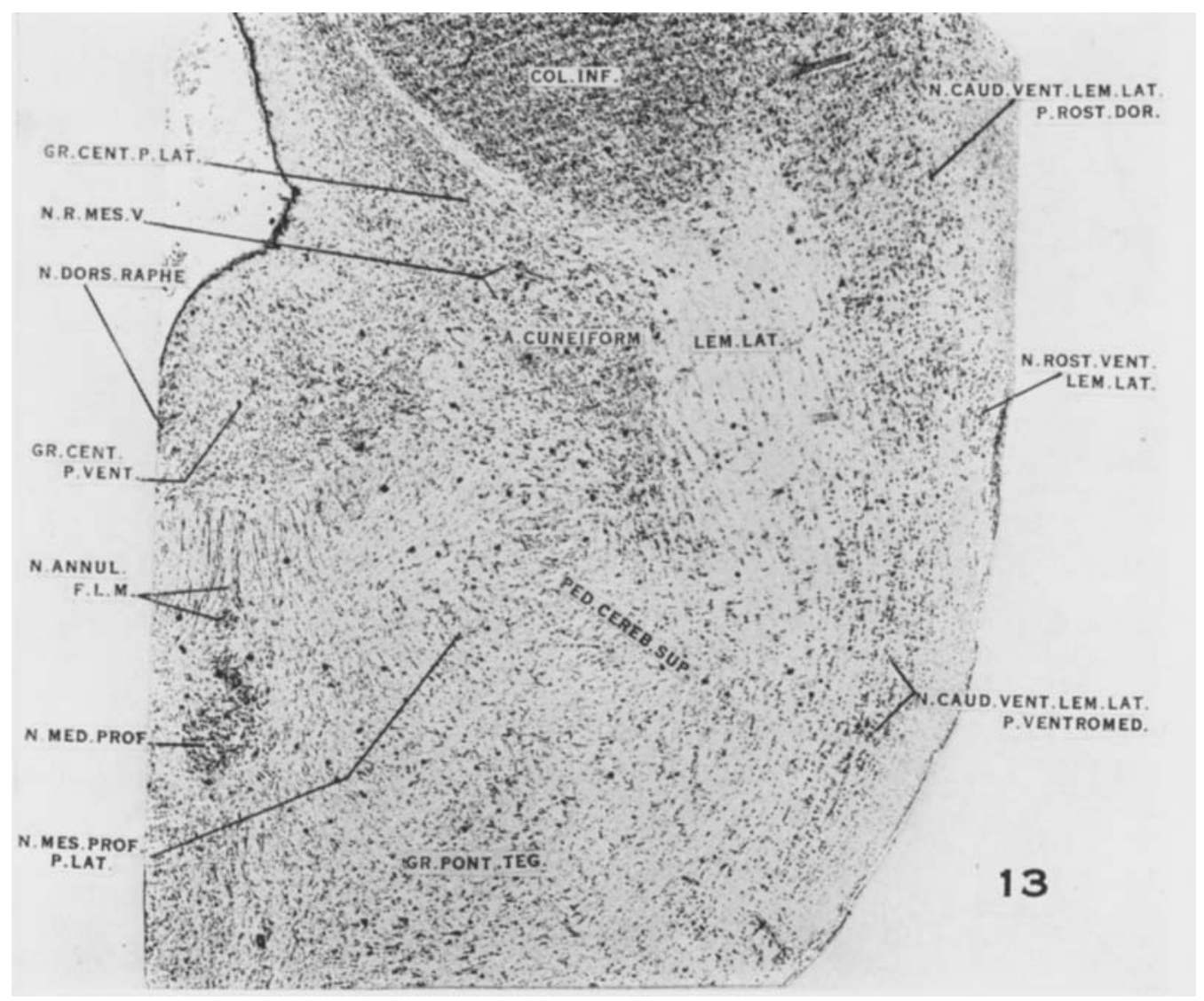

13 Rabbit brain showing the rostral portion of the caudal ventral nucleus of the lateral lemniscus. Toluidin blue. $\times 20$. 


\section{PLATE 14}

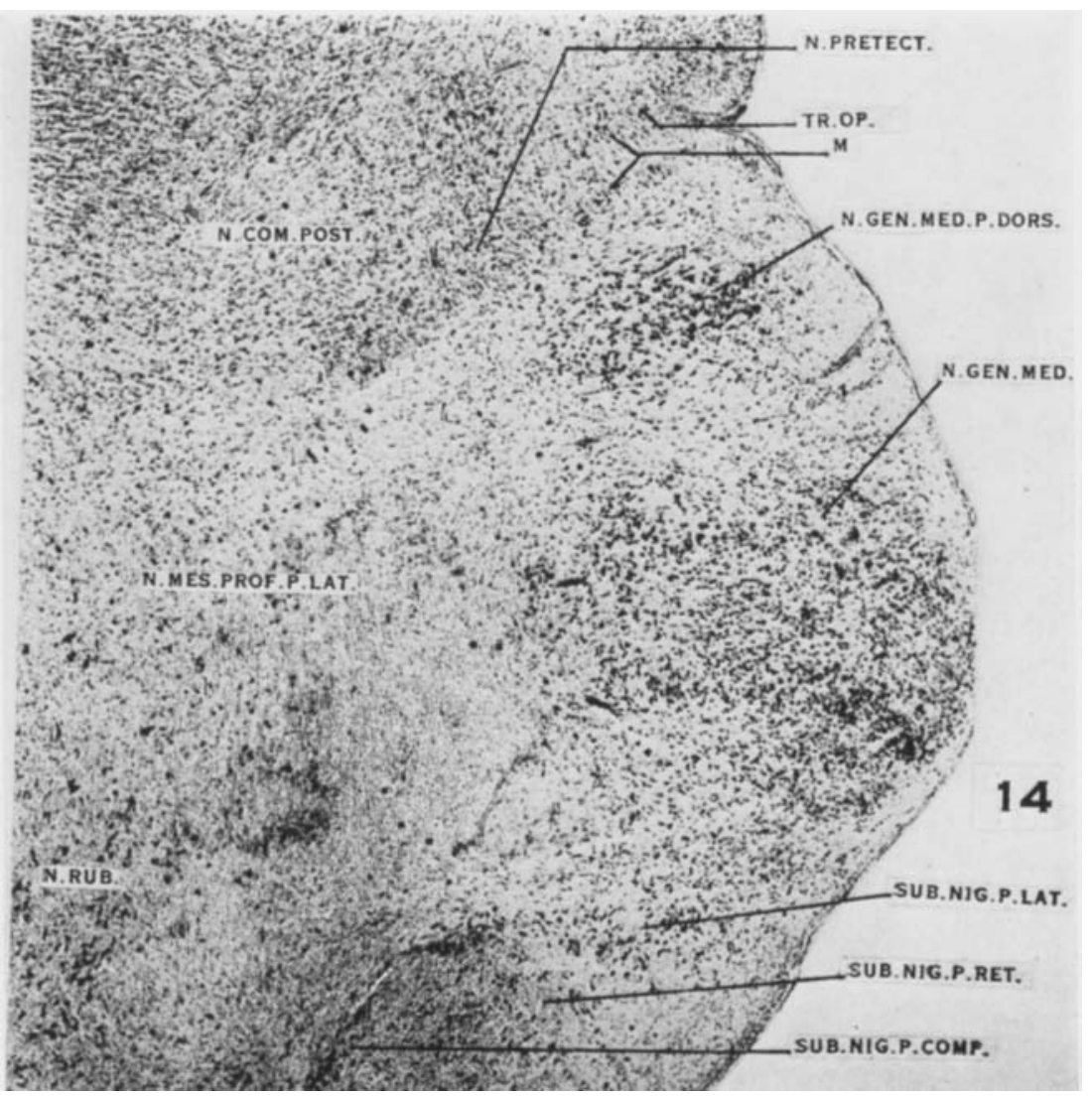

14 Rabbit brain section through the rostral midbrain, illustrating pars dorsalis of nucleus geniculatus medialis, and the large-celled nucleus of the optic tract in relation to the pretectal nucleus. Toluidin blue. $\times 20$. 